\title{
Small Extracellular Vesicles from Human Fetal Dermal Cells and Their MicroRNA Cargo: KEGG Signaling Pathways Associated with Angiogenesis and Wound Healing
}

\author{
Cinzia Maria Chinnici $\left(\mathbb{D},{ }^{1,2}\right.$ Giandomenico Amico $\mathbb{D}^{1,2}$ Alessia Gallo, ${ }^{2}$ Gioacchin Iannolo ${ }^{1}{ }^{2}$ \\ Nicola Cuscino, ${ }^{2}$ Serena Vella, ${ }^{3}$ Claudia Carcione, ${ }^{1}$ David Nascari, ${ }^{1,4}$ \\ and Pier Giulio Conaldi ${ }^{2}$ \\ ${ }^{1}$ Fondazione Ri.MED, Palermo, Italy \\ ${ }^{2}$ Department of Research, IRCCS-ISMETT, Palermo, Italy \\ ${ }^{3}$ Innovation and Development Department, Anemocyte Srl, Gerenzano, Italy \\ ${ }^{4} \mathrm{McGowan}$ Institute for Regenerative Medicine, University of Pittsburgh, Pittsburgh PA, USA
}

Correspondence should be addressed to Cinzia Maria Chinnici; cchinnici@fondazionerimed.com

Received 21 April 2020; Revised 8 July 2020; Accepted 21 July 2020; Published 13 August 2020

Academic Editor: Kar Wey Yong

Copyright ( 2020 Cinzia Maria Chinnici et al. This is an open access article distributed under the Creative Commons Attribution License, which permits unrestricted use, distribution, and reproduction in any medium, provided the original work is properly cited.

\begin{abstract}
The use of cell secreted factors in clinical settings could be an alternative to conventional cell therapy, with the advantage of limiting concerns generally associated with traditional cell transplantation, such as tumorigenicity, immunoreactivity, and carrying of infections. Based on our published data, we predict a potential role for extracellular vesicles (EVs) in contributing to the proangiogenic activity of human fetal dermal cell secretome. Depletion of nanosized EVs from secretome significantly impaired its ability to induce formation of mesh-like structures in vitro. The isolated EVs were characterized for size and concentration by nanoparticle tracking analysis, and for protein markers $\left(\mathrm{Rab5}^{+}, \mathrm{Alix}^{+}, \mathrm{CD}^{+} 3^{+}\right.$, and calnexin $\left.{ }^{-}\right)$. The microRNA profile of EVs revealed 87 microRNAs significantly upregulated ( $\geq 15$-fold increase) in fetal compared to adult dermal cell-derived EVs. Interestingly, these upregulated microRNAs included microRNAs with a validated role in angiogenesis according to literature. Moreover, the DIANA-TarBase v7.0 analysis confirmed enrichment in the KEGG signaling pathways associated with angiogenesis and wound healing, with the identification of putative target genes including thrombospondin 1 . To validate the in silico data, EVs were also characterized for total protein contents. When tested in in vitro angiogenesis, fetal dermal cell-derived EVs were more effective than their adult counterpart in inducing formation of complete mesh-like structures. Furthermore, treatment of fibroblasts with fetal dermal-derived EVs determined a 4-fold increase of thrombospondin 1 protein amounts compared with the untreated fibroblasts. Finally, visualization of CSFE-labeled EVs in the cytosol of target cells suggested a successful uptake of these particles at 4-8 hours of incubation. We conclude that EVs are important contributors of the proangiogenic effect of fetal dermal cell secretome. Hence, EVs could also serve as vehicle for a successful delivery of microRNAs or other molecules of therapeutic interest to target cells.
\end{abstract}

\section{Introduction}

The list of clinical conditions related to insufficient angiogenesis is wide, ranging from cardiovascular diseases to impaired wound healing [1]. Therefore, there is a great interest in developing clinical strategies ensuring vasculature formation, such as delivery of different cell populations, or administra- tion of proangiogenic growth factors. Among the cell-based therapies, the use of mesenchymal stromal cells (MSCs), which are closely related to pericytes and produce diverse proangiogenic factors, is a promising approach with the potential to stimulate vasculature tissue development [2].

MSC-based therapy applied to regenerative medicine counts hundreds of registered clinical trials with excellent 
records of safety and efficacy (http://www.clinicaltrials.gov and http://www.clinicaltrialsregister.eu). Despite earlier works ascribing the therapeutic effects of MSCs to their ability to engraft and differentiate to form new permanent tissues, the current consensus view is that MSCs are shortlived after delivery and exert therapeutic benefits through secretion of bioactive factors [3]. In support of MSC paracrine activity, animal studies have shown that administration of MSC-derived soluble factors recapitulates the effects of cell-based therapy [4]. Consequently, the attention has been brought to the vast array of molecules produced by MSCs $[5,6]$. The mixture of growth factors, cytokines, chemokines, and extracellular vesicles (EVs) released by cells is known as secretome and can be collected as cell culture conditioned medium $(\mathrm{CM})$.

Human fetal skin cell therapy has been used to replace older skin cell therapy to treat patients with skin ulcers $[7,8]$, as well as burns $[9,10]$, thus resulting in a safe and more efficacious procedure. At that time, the authors suggested the differential gene expression profiling observed in fetal versus adult skin cells as responsible for the efficacy of fetal skin cell therapy [8]. Moreover, since no trace of fetal skin cells was found in recipient biopsies, a paracrine mechanism of healing was suggested [10]. Although an extensive characterization of cell phenotype and secreted factors was missing, those studies open up new research perspectives on the use of cell secretome for regenerative medicine applications.

In a previous study [11], we isolated human fetal dermal cells, which we named multipotent fetal dermal cells based on in vitro characteristics, such as the MSC-like immunophenotype, the multilineage differentiation potential, and the low immunogenicity. We also confirmed the practical advantages of culturing fetal skin cells in comparison to adult skin cells described by others $[7,9,10]$, including faster isolation technique and higher proliferative capacity of fetal cells. More recently [12], we used liquid chromatography and tandem mass spectrometry (LC-MS/MS) to show a set of proteins related to angiogenesis and wound healing, which were significantly upregulated in fetal dermal cell secretome compared to adult dermal cell secretome. Proteome finding was corroborated by the remarkable in vitro proangiogenic capacity of fetal dermal cell secretome compared to its adult counterpart.

In the present study, we investigated whether the presence of EVs could contribute to the biological functions of fetal dermal cell secretome. EVs are released by several cell types and are essential for cell-to-cell communication [13]. These particles are internalized by target cells [14] and once in the cytosol, discharge their material such as proteins, mRNAs, and microRNAs (miRNAs). Administration of MSC-derived EVs has been shown to have beneficial effects in various animal models of organ injury by regulating angiogenesis, cell proliferation, cell migration, and collagen synthesis $[15,16]$. Nevertheless, EV-based therapy for skin repair consists only of one registered clinical trial aims at studying the effects of plasma-derived exosomes on cutaneous wound healing (http://www.clinicaltrials.gov, NCT02565264).
Herein, EVs were isolated from secretome of fetal and adult dermal cells and characterized for size and concentration by nanoparticle tracking analysis (NTA). Then, we tested the capacity of EV-depleted secretome in inducing in vitro angiogenesis and migration of target cells such as human umbilical vein endothelial cells (HUVECs) and fibroblasts. The miRNA expression profile of fetal dermal cell- vs. adult dermal cell-derived EVs was also analyzed, and a bioinformatics approach was used to identify the Kyoto Encyclopedia of Genes and Genomes (KEGG) signaling pathways most likely affected by these miRNAs. The predicted angiogenic/wound healing-related effects of fetal dermal cellderived EVs were further validated in in vitro cell-based assays of angiogenesis and cell migration by preconditioning of target cells with different concentrations of EV preparations. Finally, we investigated whether carboxyfluorescein succinimidyl ester- (CSFE-) labeled EVs from fetal dermal cells might be taken up by target cells.

\section{Materials and Methods}

2.1. Cell Procurement. Fetal skin biopsies were taken from 20- to 22-gestational-week human fetuses obtained from therapeutic abortions, according to a protocol approved by ISMETT's Institutional Research Review Board (IRRB/00/2015) and Ethics Committee. Signed informed consent form was obtained from each donor. Fetal dermal cells were isolated and characterized as previously described [11]. Adult skin biopsies (45-55-year-old donors) were provided by Istituto Humanitas (Rozzano, Milan). Fetal and adult dermal cells were isolated under the same conditions. Normal dermal fibroblasts and HUVECs were purchased from Thermo Fisher Scientific (Waltham, MA, USA) and used as target cells in in vitro cell-based assays.

\subsection{Cell Cultures, CM Collection, Isolation, and Storage of} EVs. Fetal dermal cells and adult dermal cells, previously cryopreserved in Dulbecco's modified Eagle's medium (DMEM) (Sigma-Aldrich, St. Louis, MO, USA) supplemented with $10 \%$ dimethyl sulfoxide (DMSO) (CryoSure, WAK-Chemie Medical GmbH, Steinbach, Germany) and $30 \%$ fetal bovine serum (FBS), were grown in $75 \mathrm{~cm}^{2}$ tissue flasks (SARSTEDT, Numbrecht, Germany) as previously described [11]. For CM collection, serum-free alphaminimum essential medium (MEM) (Gibco, Thermo Fisher Scientific) was added to $80 \%$ confluent cells and collected 24 hours later. EVs were isolated by differential ultracentrifugation of CM according to a protocol [17] and as previously described [18]. In brief, CM was centrifuged at $1800 \times g$ for 10 minutes to remove cell debris, centrifuged again at $17000 \times g$ for 15 minutes, and then at $160000 \times g$ for 1 hour in the ultracentrifuge (Optima MAX-XP, Beckman Coulter Inc., Irving, TX, USA). All centrifugation steps were done at $4^{\circ} \mathrm{C}$. The pellet was resuspended in phosphate-buffered saline (PBS) without $\mathrm{Ca}^{2+1} \mathrm{Mg}^{2+}$ (Sigma-Aldrich) or subjected to total protein extraction or total RNA extraction.

2.3. Characterization of EVs by Nanoparticle Tracking Analysis. Pellet particles resuspended in PBS (three fetal 
and three adult samples) were analyzed for size and concentration by nanoparticle tracking analysis (NTA) [19] using the NanoSight (NS300, Malvern Instruments, Westborough, MA, USA). Briefly, samples were diluted in PBS, $300 \mu \mathrm{l}$ of sample was loaded into the chamber, and five videos for each sample were recorded. Data analysis was performed with the NTA software and data were presented as the mean \pm standard deviation (SD) of the five videos.

\subsection{Extraction of Total RNA from EVs, Reverse Transcription} (RT), qPCR, and TaqMan Low-Density Arrays (TLDA) for miRNA Profiling. Total RNA was extracted from EVs of fetal and adult dermal cells using the miRNeasy Mini Kit (Qiagen, Hilden, Germany), according to manufacturer's instructions. The purity of isolated RNA was determined by $\mathrm{OD}_{260 / 280}$ using a NanoDrop (ND-1000, Thermo Fisher Scientific). Reverse transcription (RT) and preamplification were done using the High-Capacity cDNA Reverse Transcription Kit (Applied Biosystems, Thermo Fisher Scientific) according to manufacturer's instructions. The kit includes the Megaplex PreAmp Primers Human Pool A v2.1 and the Megaplex PreAmp Primers Human Pool B v3.0 (both primers from Applied Biosystems, Thermo Fisher Scientific). miRNA profiling of three fetal vs. three adult EV preparations was done with TaqMan Array Human MicroRNA A+B Cards (Life Technologies, Carlsbad, CA, USA), which analyzes 754 human miRNAs. PCR was done with the Applied Biosystems 7900 HT Real-Time PCR system. The expression level of each miRNA was determined by equation $2^{-\Delta \Delta C T}$. Student's $t$-test was used to calculate the $p$ value, and the threshold was set at $\leq 0.05$. Data were considered significant at a fold change $>15$. Furthermore, significantly upregulated miRNAs in fetal vs. adult samples were screened out with the online prediction software program DIANA-miRPath v.3 [20]. We selected DIANA-TarBase v7.0 for analysis and set the $p$ value $\leq 0.05$ to analyze miRNAs and their target genes. KEGG enrichment analysis was used to identify signaling pathways most enriched by our miRNAs. In order to identify single genes targeted by multiple miRNAs, KEGG analysis was performed with the "genes intersection" option.

2.5. Quantification of EV Total Protein Contents. Total protein extraction from EVs was done with radioimmunoprecipitation assay (RIPA) buffer (Thermo Fisher Scientific) supplemented with halt protease and phosphatase inhibitors cocktail (Thermo Fisher Scientific). Tissue extracts were centrifuged at $12000 \times g$ for 15 minutes at $4^{\circ} \mathrm{C}$. Total protein contents were quantified with the bicinchoninic acid (BCA) assay (Thermo Fisher Scientific) by using the Tecan Spark $10 \mathrm{M}$ microplate reader (BioExpress, VWR, Radnor, PA, USA). Both freshly isolated and frozen EV preparations were used in functional assays.

2.6. Western Blot Analysis. For biochemical characterization of EVs, $30 \mu \mathrm{g} /$ lane of total protein extracts was separated by sodium dodecyl sulfate- (SDS-) polyacrylamide gel electrophoresis and transferred to nitrocellulose membranes (BioRad Laboratories, Richmond, CA, USA). The membranes were blocked with $5 \%$ nonfat milk in T-TBS $(50 \mathrm{mmol} / \mathrm{l}$ Tris
$\mathrm{pH} 7.5,0.9 \% \mathrm{NaCl}$, and $0.1 \%$ Tween-20) (all from SigmaAldrich) overnight at $4^{\circ} \mathrm{C}$ and incubated 1 hour at room temperature with the following primary antibodies: mouse monoclonal antibody raised against recombinant human Rab5 (F-9, sc-373725, Santa Cruz Biotechnology, Santa Cruz, CA, USA; 1:500 dilution), mouse monoclonal antibody against Alix (3A9, 2171, Cell Signaling Technology, Danvers, MA, USA; $1: 1000$ dilution), and mouse monoclonal antibody against CD63 (MX-49.129.5, sc-5275, Santa Cruz Biotechnology; 1:200 dilution). As a negative marker of EVs, a rabbit monoclonal antibody against calnexin (C5C9, 2679, Cell Signaling; $1: 1000$ dilution) was used. For this latter, total protein extracts from cells were also included in the analysis.

For validation of the in silico analysis, fibroblasts were treated with $10 \mu \mathrm{g} / \mathrm{ml}$ of fetal-derived EVs for 24,48 , and 72 hours. $30 \mu \mathrm{g} /$ lane of fibroblast total protein extracts was separated by SDS polyacrylamide gel electrophoresis and transferred to nitrocellulose membranes (Bio-Rad Laboratories). The membranes were incubated 1 hour at room temperature with a rabbit monoclonal antibody against recombinant human thrombospondin 1 (THBS1) (ab267388, Abcam, Cambridge, UK; $1: 1000$ dilution). Betaactin was used as an internal loading control (sc-81178, Santa Cruz Biotechnology; $1: 1000$ dilution). After three washings with T-TBS, the membranes were incubated for 1 hour at room temperature with horseradish peroxidase-conjugated secondary antibodies (Santa Cruz Biotechnology; 1:10000 dilution). After washing, the signal was detected with an enhanced chemiluminescence reagent (ECL; Amersham, Arlington Heights, IL, USA). Densitometric analysis of Western blot analysis was done with the Image Lab software, version 6.0.1 (Bio-Rad Laboratories).

2.7. EV/CM-Induced In Vitro Angiogenesis. Serum-starved HUVECs were resuspended in serum-free culture medium supplemented with different concentrations of EVs (100, 50,10 , or $5 \mu \mathrm{g} / \mathrm{ml}$ ) from fetal and adult dermal cells. Approximately 10000 cells/well were plated in triplicate onto Matrigel from the in vitro angiogenesis assay kit (Millipore, Billerica, MA, USA) in flat bottom 96-well plastic plates (Costar Corning Inc., Costar, NY, USA). HUVECs plated in fetal dermal cell CM or in serum-free culture medium were used as positive and negative control, respectively. Plates were incubated at $37^{\circ} \mathrm{C}$ in a humidified atmosphere with $5 \% \mathrm{CO}_{2}$. Formation of mesh-like structures was monitored for 24 hours with an inverted microscope (Olympus CKX41, Tokyo, Japan) coupled with a camera (Olympus UTV0.5XC-3) for image acquisition. Numerical values (score from 0 to 5) were assigned to each pattern according to manufacturer's specifications (Millipore) and as previously described [12]. Formation of mesh-like structures was quantified by calculating the number of junctions, nodes, total mesh area, and total segments length, with ImageJ software of the Angiogenesis Analyzer plugin (https://imagej.nih .gov/ij/).

2.8. In Vitro EV/CM-Induced Cell Migration. Cell migration was monitored by using the Cellular Invasion/Migration (CIM) Plate 16 with the XCELLigence Real-Time Cell 


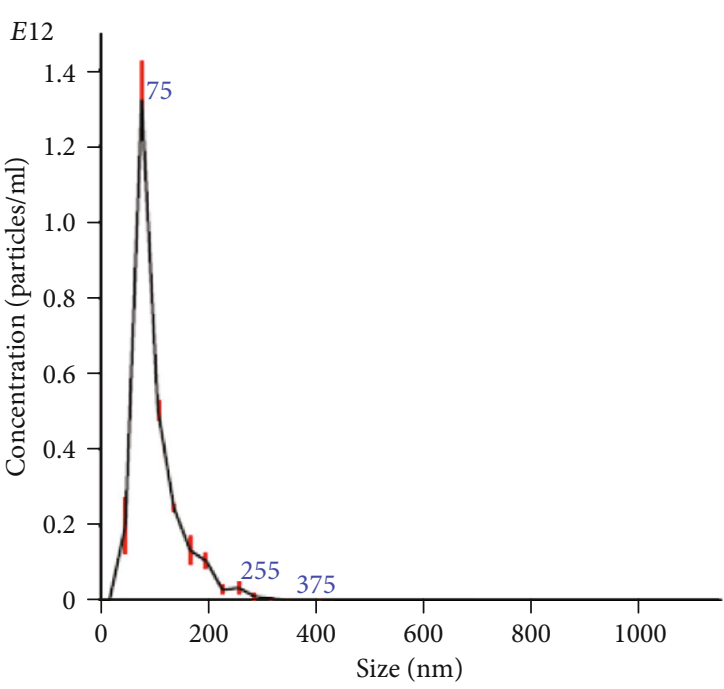

(a)

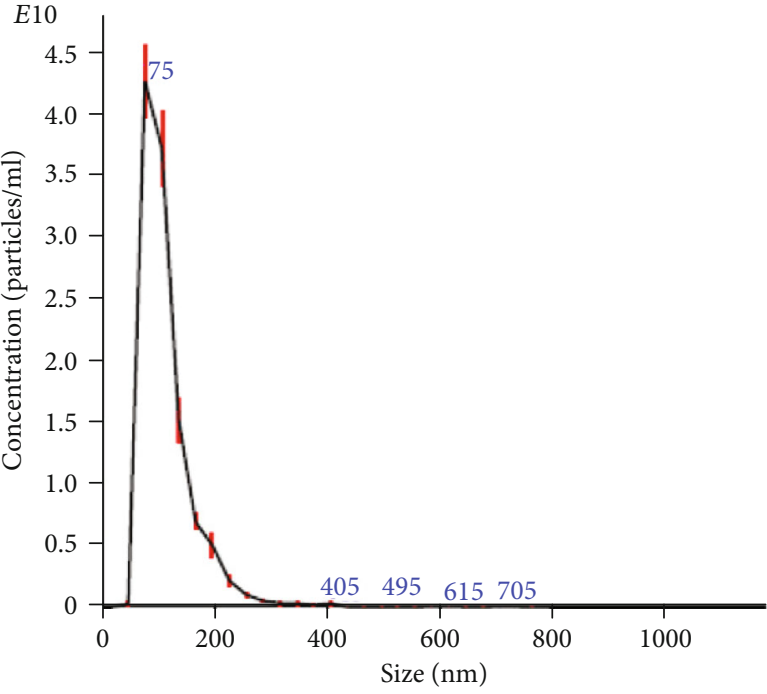

(b)

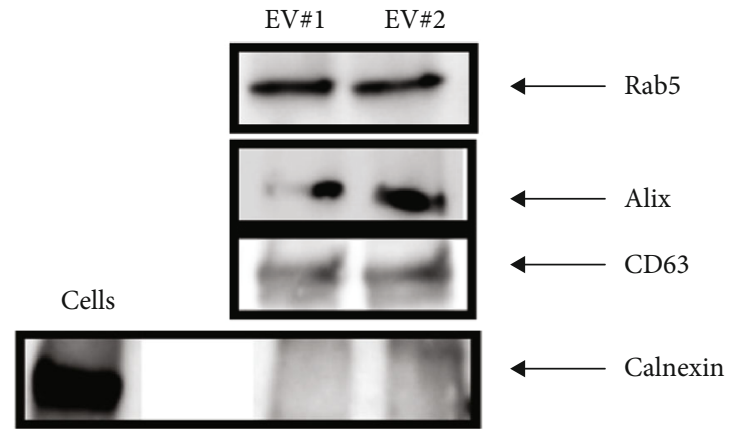

(c)

Figure 1: Physical characterization of EVs by NTA and protein expression. (a) Representative histogram of EVs isolated from secretome of fetal dermal cells showing a peak corresponding to a mode value of $77.5 \pm 0.8 \mathrm{~nm}$ size and a concentration of $2.59 \times 10^{12}$ particles $/ \mathrm{ml}$. (b) Representative histogram of EVs isolated from secretome of adult dermal cells showing a peak corresponding to a mode value of $87.2 \pm$ $2.8 \mathrm{~nm}$ size and a concentration of $1.12 \times 10^{11}$ particles $/ \mathrm{ml}$. The results shown are representative of three independent experiments. (c) Representative Western blot analysis of two fetal dermal-derived EV samples showing expression of EV markers Rab5, Alix, and CD63 in total protein extracts of pellet particles. Negative control, calnexin in cell protein extracts, and pellet particles are also shown. NTA: nanoparticle tracking analysis; EVs: extracellular vesicles; cells: total protein extracts of human fetal dermal cells; EV\#1: sample 1; EV\#2: sample 2 .

Analyzer (RTCA) dual purpose (DP) instrument (Acea Biosciences Inc., San Diego, CA, USA), which detects the realtime migration of cells [21]. Briefly, serum-starved fibroblasts were resuspended in culture medium supplemented with $100,50,10$, or $5 \mu \mathrm{g} / \mathrm{ml}$ EVs from fetal and adult dermal cells or in culture medium without EVs, and added to the upper chamber (30000 cells/chamber) of the CIM plate. Culture medium $0.5 \%$ FBS was used as chemoattractant and loaded to the lower chamber. The CIM plates were assembled into the RTCA-DP instrument and placed in the incubator at $37^{\circ} \mathrm{C}$ in a humidified atmosphere with $5 \% \mathrm{CO}_{2}$. Cell migration was recorded every 15 minutes for 7 hours. Each time point was calculated from duplicate values, and cell migration was expressed as cell index (CI) at a 7-hour time point. Analysis was performed with the RTCA Software 1.2 of the xCELLigence system.
2.9. Quantitative Analysis of EV-Depleted CM by Luminex Technology. EV-depleted CM from fetal dermal cells was subjected to quantitative evaluation by Luminex xMAP technology (Luminex 200; Luminex Corp., Austin, TX, USA), enabling the simultaneous detection of analytes. The analyzed soluble factors included human growth factors such as VEGF-A and HGF, and chemokines with a documented role in angiogenesis and wound healing, such SDF-1 alpha, MCP-1, IL-8, and GRO-alpha. These factors were included in a customized panel (ProcartaPlex, Thermo Fisher Scientific). Briefly, undiluted or 1:10 diluted CM was loaded into the multiplex and processed according to manufacturer's instructions. Concentration of soluble factors was calculated by using software provided by the manufacturer, and the results normalized to the total number of attached cells. The concentration of soluble factors was expressed as $\mathrm{pg} / \mathrm{ml}$ 
TABLE 1: EV-derived miRNAs found highly expressed in fetal samples (Ct values $\leq 26$ ), which were also upregulated compared to adult samples (see also Supplemental Material S1).

\begin{tabular}{|c|c|c|c|c|}
\hline miRNA name & Role in angiogenesis/tissue regeneration & References & $\begin{array}{l}\text { Fold increase in fetal } \\
\text { vs. adult samples }\end{array}$ & $p$ value \\
\hline hsa-let-7b-5p & It targets VEGF gene; validated role in angiogenesis & $\begin{array}{c}\text { Hua et al., } 2006 \text { [36]; } \\
\text { Landskroner-Eiger et al., } 2013 \\
{[34]}\end{array}$ & 26.2091 & 0.0074 \\
\hline hsa-let-7g-5p & Validated role in angiogenesis & $\begin{array}{l}\text { Landskroner-Eiger et al., } 2013 \\
\text { [34] }\end{array}$ & 175.3585 & 0.021 \\
\hline hsa-miR-10a-5p & $\begin{array}{l}\text { Validated role in angiogenesis; angiogenesis } \\
\text { influencer }\end{array}$ & $\begin{array}{l}\text { Landskroner-Eiger et al., } 2013 \\
\text { [34] }\end{array}$ & 242.9505 & 0.03 \\
\hline hsa-miR-10b-3p & & & 17.9198 & 0.0346 \\
\hline hsa-miR-15b-5p & $\begin{array}{l}\text { Angiogenesis regulator; delivered in regenerative } \\
\text { medicine for cardiac repair }\end{array}$ & $\begin{array}{l}\text { Curtin et al., } 2018 \text { [29]; } \\
\text { Wang \& Olson, } 2009 \text { [39] }\end{array}$ & 2624.268 & 0.0003 \\
\hline hsa-miR-16-5p & $\begin{array}{l}\text { Angiogenesis regulator; it targets VEGF gene; } \\
\text { regulator of angiogenesis; induces tube formation of } \\
\text { HUVECs }\end{array}$ & $\begin{array}{c}\text { Hua et al., } 2006[36] ; \\
\text { Poliseno et al., } 2006[78] \\
\text { Suarez \& Sessa, } 2009[38] ; \\
\text { Wang \& Olson, } 2009[39]\end{array}$ & 149.6445 & 0.0183 \\
\hline hsa-miR-17-5p & Angiogenesis regulator; it targets VEGF gene & $\begin{array}{c}\text { Caporali \& Emanueli, } 2011[33] \\
\text { Hua et al., } 2006 \text { [36] } \\
\text { Wang \& Olson, } 2009[39]\end{array}$ & 133.7475 & 0.0032 \\
\hline hsa-miR-19a-3p & Validated role in angiogenesis & $\begin{array}{l}\text { Landskroner-Eiger et al., } 2013 \\
\text { [34]; Wang \& Olson, } 2009 \text { [39] }\end{array}$ & 51.8807 & 0.0114 \\
\hline hsa-miR-19b-3p & Angiogenesis regulator & $\begin{array}{l}\text { Caporali \& Emanueli, } 2011 \text { [33]; } \\
\text { Wang \& Olson, } 2009 \text { [39] }\end{array}$ & 109.3557 & 0.0044 \\
\hline hsa-miR-20a-5p & It targets VEGF gene; validated role in angiogenesis & $\begin{array}{l}\text { Hua et al., } 2006 \text { [36]; } \\
\text { Landskroner-Eiger et al., } 2013 \\
\text { [34]; Wang \& Olson, } 2009 \text { [39] }\end{array}$ & 56.7629 & 0.0004 \\
\hline hsa-miR-21-5p & Angiogenesis regulator; wound healing regulator & $\begin{array}{l}\text { Wang \& Olson, } 2009 \text { [39]; Wang } \\
\text { et al., } 2012 \text { [32] }\end{array}$ & 157.6826 & 0.0046 \\
\hline hsa-miR-24-3p & Highly expressed by endothelial cells & $\begin{array}{l}\text { Suarez \& Sessa, } 2009[38] \\
\quad \text { Zhou et al., } 2011[40]\end{array}$ & 25.4984 & 0.0059 \\
\hline hsa-miR-26a-5p & $\begin{array}{l}\text { Proregenerative (it promotes osteogenesis- } \\
\text { angiogenesis in mouse) }\end{array}$ & Li et al., 2013 [47] & 132.6638 & 0.0122 \\
\hline hsa-miR-26b-5p & Tissue repair; remodeling in wound healing & $\begin{array}{l}\text { Banerjee \& Sen, } 2013[31] \\
\quad \text { Sen et al., } 2015 \text { [30] }\end{array}$ & 95.4933 & 0.0183 \\
\hline hsa-miR-27b-3p & It targets VEGF gene; validated role in angiogenesis & $\begin{array}{l}\text { Hua et al., } 2006 \text { [36]; } \\
\text { Landskroner-Eiger et al., } 2013 \\
\text { [34]; Wang \& Olson, 2009 [39]; } \\
\text { Zhou et al., 2011 [40] }\end{array}$ & 950.021 & 0.0096 \\
\hline hsa-miR-28-3p & & & 49.9995 & 0.0082 \\
\hline hsa-miR-29b-3p & $\begin{array}{c}\text { Regulator of tissue regeneration; proregenerative } \\
\text { (delivered for ECM remodeling in fibrosis } \\
\text { treatment) }\end{array}$ & $\begin{array}{l}\text { Monaghan et al., } 2014 \text { [42]; } \\
\text { van Rooij et al., } 2008 \text { [43] }\end{array}$ & 61.9175 & 0.0105 \\
\hline hsa-miR-30a-3p & It targets VEGF gene; endothelial cell modulator & $\begin{array}{l}\text { Bridge et al., } 2012[35] \\
\text { Hua et al., } 2006 \text { [36] }\end{array}$ & 185.51 & 0.0099 \\
\hline hsa-miR-30b-5p & $\begin{array}{l}\text { Angiogenesis regulator; endothelial cell modulators; } \\
\text { it targets VEGF gene }\end{array}$ & $\begin{array}{l}\text { Bridge et al., } 2012 \text { [35]; } \\
\text { Hua et al., } 2006 \text { [36] }\end{array}$ & 32.3336 & 0.0004 \\
\hline hsa-miR-30c-5p & Endothelial cell modulator & Bridge et al., 2012 [35] & 30.1373 & 0.0002 \\
\hline hsa-miR-30e-3p & Endothelial cell modulator & Bridge et al., 2012 [35] & 41.2049 & 0.0041 \\
\hline hsa-miR-31-5p & Angiogenesis regulator; wound healing & $\begin{array}{l}\text { Li et al., } 2015 \text { [79]; } \\
\text { Wang et al., } 2012 \text { [32] }\end{array}$ & 60.803 & 0.0027 \\
\hline hsa-miR-31-3p & Angiogenesis regulator; wound healing & $\begin{array}{l}\text { Li et al., } 2015 \text { [79]; } \\
\text { Wang et al., } 2012 \text { [32] }\end{array}$ & 229.5474 & 0.0097 \\
\hline hsa-miR-34a-5p & It targets VEGF gene & & 2254.5936 & 0 \\
\hline
\end{tabular}


TABle 1: Continued.

\begin{tabular}{|c|c|c|c|c|}
\hline miRNA name & Role in angiogenesis/tissue regeneration & References & $\begin{array}{l}\text { Fold increase in fetal } \\
\text { vs. adult samples }\end{array}$ & $p$ value \\
\hline hsa-miR-92a-3p & Validated role in angiogenesis & $\begin{array}{c}\text { Curtin et al., } 2018 \text { [29]; } \\
\text { Landskroner-Eiger et al., 2013 } \\
\text { [34]; Wang \& Olson, } 2009 \text { [39] }\end{array}$ & 32.781 & 0.0001 \\
\hline hsa-miR-93-3p & & & 149.3753 & 0.0065 \\
\hline hsa-miR-99b-3p & Angiogenesis promoter & Kane et al., 2012 [37] & 37.2967 & 0.0134 \\
\hline hsa-miR-99b-5p & Angiogenesis promoter & Kane et al., 2012 [37] & 41.1216 & 0.0031 \\
\hline hsa-miR-103a-3p & & & 809.2304 & 0.008 \\
\hline hsa-miR-106a-5p & It targets VEGF gene; regulator of angiogenesis & Hua et al., 2006 [36] & 67.8178 & 0.0047 \\
\hline hsa-miR-106b-5p & It targets VEGF gene; regulator of angiogenesis & $\begin{array}{c}\text { Hua et al., } 2006 \text { [36]; } \\
\text { Landskroner-Eiger et al., } 2013 \\
\text { [34] }\end{array}$ & 56.2099 & 0.0084 \\
\hline hsa-miR-125a-5p & Tube formation of HUVECs; it targets VEGF gene & $\begin{array}{l}\text { Hua et al., } 2006 \text { [36]; } \\
\text { Poliseno et al., } 2006 \text { [78] }\end{array}$ & 128.8981 & 0.0061 \\
\hline hsa-miR-125b-5p & Angiogenesis regulator; tube formation of HUVECs & $\begin{array}{l}\text { Poliseno et al., } 2006 \text { [78]; } \\
\text { Zhou et al., } 2015 \text { [80] }\end{array}$ & 18.6552 & 0.0041 \\
\hline hsa-miR-127-3p & & & 19.2386 & 0.0001 \\
\hline hsa-miR-132-3p & $\begin{array}{l}\text { Validated role in angiogenesis during chronic } \\
\text { wound healing; proregenerative (it promotes } \\
\text { angiogenesis in myocardial infarction) }\end{array}$ & $\begin{array}{l}\text { Landskroner-Eiger et al., } 2013 \\
\text { [34]; Li et al., } 2017 \text { [81]; Ma et al., } \\
2018 \text { [44] }\end{array}$ & 3664.7066 & 0.0034 \\
\hline hsa-miR-136-3p & & & 164.0836 & 0.0268 \\
\hline hsa-miR-138-5p & & & 52.6792 & 0.0162 \\
\hline hsa-miR-145-5p & Angiogenesis regulator & Fan et al., 2012 [82] & 42.2841 & 0.0067 \\
\hline hsa-miR-146a-3p & Wound healing (inflammatory phase) & Banerjee \& Sen, 2013 [31] & 172.0832 & 0.0135 \\
\hline hsa-miR-146b-3p & $\begin{array}{l}\text { Wound healing (inflammatory phase); angiogenesis } \\
\text { promoter }\end{array}$ & $\begin{array}{c}\text { Ahn et al., } 2013 \text { [83]; } \\
\text { Banerjee \& Sen, } 2013 \text { [31] }\end{array}$ & 203.771 & 0.0161 \\
\hline hsa-miR-149-5p & Scarless wound healing & Lang et al., 2017 [84] & 37.5122 & 0.0102 \\
\hline hsa-miR-151a-5p & & & 126.8167 & 0.005 \\
\hline hsa-miR-151a-3p & & & 17.732 & 0.0246 \\
\hline hsa-miR-152-3p & & & 20.0452 & 0.0097 \\
\hline hsa-miR-155-5p & $\begin{array}{c}\text { Wound healing (inflammatory phase); amyotrophic } \\
\text { lateral sclerosis; anti-inflammatory action; } \\
\text { angiogenesis regulator }\end{array}$ & $\begin{array}{c}\text { Banerjee \& Sen, } 2015 \text { [31]; Curtin } \\
\text { et al., } 2018 \text { [29]; Suarez \& Sessa, } \\
2009 \text { [38] }\end{array}$ & 32.5772 & 0.04 \\
\hline hsa-miR-181a-5p & Angiogenesis promoter & Kane et al., 2012 [37] & 112.4827 & 0.0011 \\
\hline hsa-miR-186-5p & & & 78.0074 & 0.0165 \\
\hline hsa-miR-191-5p & It may regulate the angiogenic actions of VEGF & $\begin{array}{l}\text { Landskroner-Eiger et al., } 2013 \\
\text { [34] }\end{array}$ & 66.0569 & 0.0121 \\
\hline hsa-miR-193a-5p & It targets VEGF gene & Hua et al., 2006 [36] & 108.2673 & 0.0061 \\
\hline hsa-miR-193b-3p & Proregenerative (chondrogenesis) & Meng et al., 2018 [45] & 16.6788 & 0.0057 \\
\hline hsa-miR-197-3p & & & 47.9232 & 0.01 \\
\hline hsa-miR-199a-3p & $\begin{array}{l}\text { It targets VEGF gene; proregenerative (cardiac } \\
\text { regeneration) }\end{array}$ & $\begin{array}{l}\text { Hua et al., } 2006 \text { [36]; Lesizza et al., } \\
\qquad 2017 \text { [46] }\end{array}$ & 79.9505 & 0.0112 \\
\hline hsa-miR-214-3p & & & 34.8695 & 0.0131 \\
\hline hsa-miR-214-5p & It targets VEGF gene & Hua et al., 2006 [36] & 493.6614 & 0.0151 \\
\hline hsa-miR-218-5p & Validated role in angiogenesis & $\begin{array}{l}\text { Landskroner-Eiger et al., } \\
\qquad 2013 \text { [34] }\end{array}$ & 32.9227 & 0.0092 \\
\hline hsa-miR-221-3p & Validated role in angiogenesis & $\begin{array}{l}\text { Landskroner-Eiger et al., } \\
\qquad 2013 \text { [34] }\end{array}$ & 27.5391 & 0.0003 \\
\hline hsa-miR-222-3p & $\begin{array}{l}\text { Angiogenesis in wound healing; validated role in } \\
\text { angiogenesis }\end{array}$ & $\begin{array}{l}\text { Banerjee \& Sen, } 2015 \text { [31]; } \\
\text { Landskroner-Eiger et al., } \\
\qquad 2013 \text { [34] }\end{array}$ & 38.7974 & 0.0103 \\
\hline hsa-miR-224-5p & & & 21.5539 & 0.0039 \\
\hline
\end{tabular}


TABle 1: Continued.

\begin{tabular}{|c|c|c|c|c|}
\hline miRNA name & Role in angiogenesis/tissue regeneration & References & $\begin{array}{l}\text { Fold increase in fetal } \\
\text { vs. adult samples }\end{array}$ & $p$ value \\
\hline hsa-miR-320a & It targets VEGF gene; validated role in angiogenesis & $\begin{array}{c}\text { Hua et al., } 2006 \text { [36]; } \\
\text { Landskroner-Eiger et al., } \\
2013[34]\end{array}$ & 56.2268 & 0.0086 \\
\hline hsa-miR-323a-3p & & & 686.8069 & 0.0163 \\
\hline hsa-miR-324-3p & & & 137.7004 & 0.0144 \\
\hline hsa-miR-331-3p & It targets VEGF gene & Hua et al., 2006 [36] & 43.6136 & 0.0043 \\
\hline hsa-miR-342-3p & & & 169.8914 & 0.0114 \\
\hline hsa-miR-345-5p & & & 200.3964 & 0.0134 \\
\hline hsa-miR-365a-3p & & & 526.7213 & 0.0115 \\
\hline hsa-miR-370-3p & & & 99.3169 & 0.0081 \\
\hline hsa-miR-374a-5p & & & 44.7501 & 0.0225 \\
\hline hsa-miR-376a-3p & & & 216.5826 & 0.0246 \\
\hline hsa-miR-376c-3p & & & 216.5826 & 0.0246 \\
\hline hsa-miR-382-5p & & & 6102.4887 & 0.0009 \\
\hline hsa-miR-409-3p & & & 173.9373 & 0.0097 \\
\hline hsa-miR-411-5p & & & 99.6678 & 0.0353 \\
\hline hsa-miR-424-3p & & & 482.6326 & 0.0137 \\
\hline hsa-miR-432-5p & & & 125.5471 & 0.0385 \\
\hline hsa-miR-433-3p & & & 778.7489 & 0.0057 \\
\hline hsa-miR-455-5p & & & 611.2326 & 0.0122 \\
\hline hsa-miR-484 & & & 85.625 & 0.0066 \\
\hline hsa-miR-487b-3p & & & 131.5413 & 0.0028 \\
\hline hsa-miR-493-3p & & & 1303.6278 & 0.0053 \\
\hline hsa-miR-532-3p & & & 42.572 & 0.0015 \\
\hline hsa-miR-532-5p & Angiogenesis & Slater et al., 2018 [85] & 1363.2918 & 0.0072 \\
\hline hsa-miR-539-5p & & & 350.9595 & 0.0063 \\
\hline hsa-miR-574-3p & & & 59.5134 & 0.0121 \\
\hline hsa-miR-625-3p & & & 77.7476 & 0.002 \\
\hline hsa-miR-708-5p & & & 59.2604 & 0.0013 \\
\hline hsa-miR-766-3p & & & 1533.4818 & 0.016 \\
\hline hsa-miR-886-5p & & & 75.0277 & 0.0048 \\
\hline hsa-miR-1290 & & & 24.3418 & 0.0021 \\
\hline
\end{tabular}

Plotted values (mean $\pm \mathrm{SD})$ represent fetal samples $(n=3)$ compared to adult samples $(n=3)$.

$/ 1.5 \times 10^{6}$ cells $/ 24$ hours. Data from EV-depleted CM were compared with those from whole CM.

2.10. EV Labeling and Cellular Uptake Assay. EVs from fetal dermal cells were labeled with CSFE (Thermo Fisher Scientific) according to manufacturer's instructions with minor modifications. Briefly, 1:1000 diluted CSFE was added to $10 \mu \mathrm{g}$ of $\mathrm{EV}$ preparation and incubated at $37^{\circ} \mathrm{C}$ for 15 minutes. $1 \mathrm{ml}$ of $1 \%$ bovine serum albumin (BSA) (SigmaAldrich) was added to stop the labeling, and the mixture was ultracentrifuged at $100000 \times g$ for 70 minutes at $4^{\circ} \mathrm{C}$. The supernatant was discharged, the pellet resuspended in serum-free DMEM, and EV labeling was verified by flow cytometry with a FACS Canto II (Becton Dickinson, BD, Franklin Lake, NJ, USA) in a log range by using $50 \mathrm{~nm}$ diameter reference beads as size standard (MicroBeads, Miltenyi, Bergisch Gladbach, Germany), as previously described [22].
Fibroblasts and HUVECs previously grown to $60 \%$ confluence in 4-well glass chamber slides were incubated with DMEM containing CSFE-labeled EVs at a ratio $1 \mu \mathrm{g}$ EVs per 10000 adherent cells. At the end of incubation time (2, 4 , and 8 hours), cells were washed twice with PBS and fixed with $4 \%$ paraformaldehyde/PBS for 10 minutes at room temperature. Nuclei were stained with DAPI (Sigma-Aldrich) and then mounted with Permafluor and a coverslip (Thermo Fisher Scientific). Cellular uptake of EVs was visualized under a Leica confocal station (Leica SP5 confocal system) mounted on a Leica DM6000 inverted microscope (Leica Microsystems Inc., Buffalo Grove, IL, USA).

2.11. Statistical Analysis. For NTA and miRNAs analysis, three fetal-derived and three adult-derived EV samples were analyzed. For in vitro angiogenesis, four different samples corresponding to treatment with fetal-derived EVs and three 
TABLE 2: KEGG signaling pathways and their association with angiogenesis and wound healing.

\begin{tabular}{|c|c|c|c|}
\hline KEGG signaling pathway & Role in angiogenesis/wound healing & References & $\log _{10}(p$ value $)$ \\
\hline Adherens junction & Wound closure & Fenteany et al., 2000 [47] & $5.10 E-07$ \\
\hline HIPPO & Organ regeneration & $\begin{array}{l}\text { Juan \& Hong, } 2016 \text { [48]; Lee et al., } 2014 \\
\text { [49]; Zhao et al., } 2011 \text { [51]; Wang et al., } \\
2017 \text { [50] }\end{array}$ & $3.73 E-06$ \\
\hline p53 & Promotes VEGF expression and angiogenesis & Farhang Ghahremani et al., 2013 [52] & $9.63 E-06$ \\
\hline TGF-beta & Skin wound healing & $\begin{array}{l}\text { Finnson et al., } 2013 \text { [53]; Ramirez et al., } \\
\qquad 2014 \text { [54] }\end{array}$ & $2.39 E-05$ \\
\hline ECM-receptor interaction & Wound repair & Olczyk et al., 2014 [55] & $4.53 E-05$ \\
\hline Focal adhesion & Cell migration; angiogenesis & Zhao \& Guan, 2011 [56] & 0.000175201 \\
\hline mTOR & $\begin{array}{l}\text { Interconnected to PI3K-Akt pathway to accelerate } \\
\text { epithelial wound healing; angiogenesis }\end{array}$ & $\begin{array}{l}\text { Castilho et al., } 2013 \text { [56]; Karar \& } \\
\text { Maity, } 2011 \text { [59] }\end{array}$ & 0.000176029 \\
\hline HIF-1 & $\begin{array}{c}\text { Accelerating wound healing by enhancing } \\
\text { angiogenesis }\end{array}$ & Hong et al., 2014 [60] & 0.000538735 \\
\hline ErbB & $\begin{array}{c}\text { Mediates proliferation and migration of keratinocytes } \\
\text { in wound healing (ErbB1) }\end{array}$ & Pastore et al., 2008 [61] & 0.001490837 \\
\hline FoxO & $\begin{array}{l}\text { Upstream in the activation of both TGF-beta and } \\
\text { PI3K-Akt signaling pathways }\end{array}$ & & 0.002880647 \\
\hline Wnt & Participates to each stage of the healing process & Whyte et al., 2012 [62] & 0.00326995 \\
\hline Notch & $\begin{array}{l}\text { Angiogenesis and endothelial cell formation; essential } \\
\text { in organ regeneration; vasculature repair after brain } \\
\text { trauma and wound healing }\end{array}$ & $\begin{array}{l}\text { Carlson et al., } 2007 \text { [63]; Raya et al., } \\
2003 \text { [66]; Ran et al., } 2015 \text { [65]; } \\
\text { Chigurupati et al., } 2007 \text { [64] }\end{array}$ & 0.004876559 \\
\hline Neurotrophin & Novel regulator of angiogenesis & Kraemer \& Hempstead, 2003 [67] & 0.009582793 \\
\hline MAPK & Skin reepithelialization & Deng et al., 2006 [68] & 0.008652606 \\
\hline Insulin & Upstream to PI3k/Akt and mTOR & Karar \& Maity, 2011 [59] & 0.014139516 \\
\hline
\end{tabular}

DIANA tool analysis of the 87 miRNAs considered significantly upregulated in fetal vs. adult dermal cell-derived EVs.

different samples corresponding to the remaining treatments (adult-derived EVs, fetal-derived CM, and the corresponding EV-depleted CM) were analyzed. For cell migration assay, three different samples of each condition were analyzed (fetal-derived EVs, adult-derived EVs, fetal CM, and the corresponding EV-depleted CM). For quantitative analysis by Luminex of whole CM vs. EV-depleted CM, ten fetal CM samples were analyzed. Data were analyzed with $R[23]$ and expressed as the mean \pm SD. Data from two different groups were compared with Student's $t$-test. Differences between the groups were considered significant at a $p$ value of $\leq 0.05$.

Angiogenesis data were analyzed with GraphPad Prism 8.4.2 and expressed as the mean \pm SD. Data from each condition were compared to treatment with fetal-derived EVs with the one-way ANOVA.

\section{Results}

3.1. Characterization of EVs by Nanoparticle Tracking Analysis and Protein Marker Expression. The NTA of pellet preparations obtained by differential ultracentrifugation of CM from fetal and adult dermal cells indicated a "mode" diameter size (representing the size of the most abundant particles in a sample preparation) consistent with that of "small EVs" (<200 nm [24]). The mode sizes of a representative fetal sample $(77.5 \pm 0.8 \mathrm{~nm})$ and that of a representative adult sample $(87.2 \pm 2.8 \mathrm{~nm})$ are shown in Figure $1(\mathrm{a})$ and Figure 1(b), respectively. The concentration of EVs from both fetal and adult cells was in a range of $10^{11}-10^{12}$ particles/ml. Moreover, characterization by Western blot analysis revealed that pellet particles expressed Rab5, Alix, and CD63 proteins, and while were negative for calnexin protein, this latter found in total protein extracts from human fetal dermal cells (Figure 1(c)).

3.2. Differential Expression of EV miRNAs and Their Association with Signaling Pathways Related to Angiogenesis and Wound Healing. We found 87 highly expressed miRNAs (Ctvalues $\leq 26)$ in fetal dermal cell-derived EVs. These highly expressed miRNAs were also considered significantly upregulated in fetal compared to adult dermal cell-derived EVs (Table 1; Supplemental Material S1). In addition, 21 miRNAs had a validated role in angiogenesis according to literature (Table 1; Supplemental Material S1).

KEGG analysis with DIANA-TarBase of these $87 \mathrm{miR}$ NAs evidenced 85 signaling pathways, 15 of which related to angiogenesis/wound healing (Table 2; Supplemental Material S2), (Figure 2). By setting 29 as a threshold (genes intersection) [20], we selected 4 signaling pathways associated with angiogenesis and wound healing from the obtained list (Figure 3; Supplemental Material S3). In particular, we found 46 out of 87 miRNAs enriched in ECM-receptor interaction signaling pathway, with two putative target genes, THBS1 and fibronectin (FN1) (Supplemental Material S3); 69 miRNAs enriched in the p53 signaling pathway with the target genes THBS1, cyclin D1 (CCND1), cyclin D2 (CCND2), 


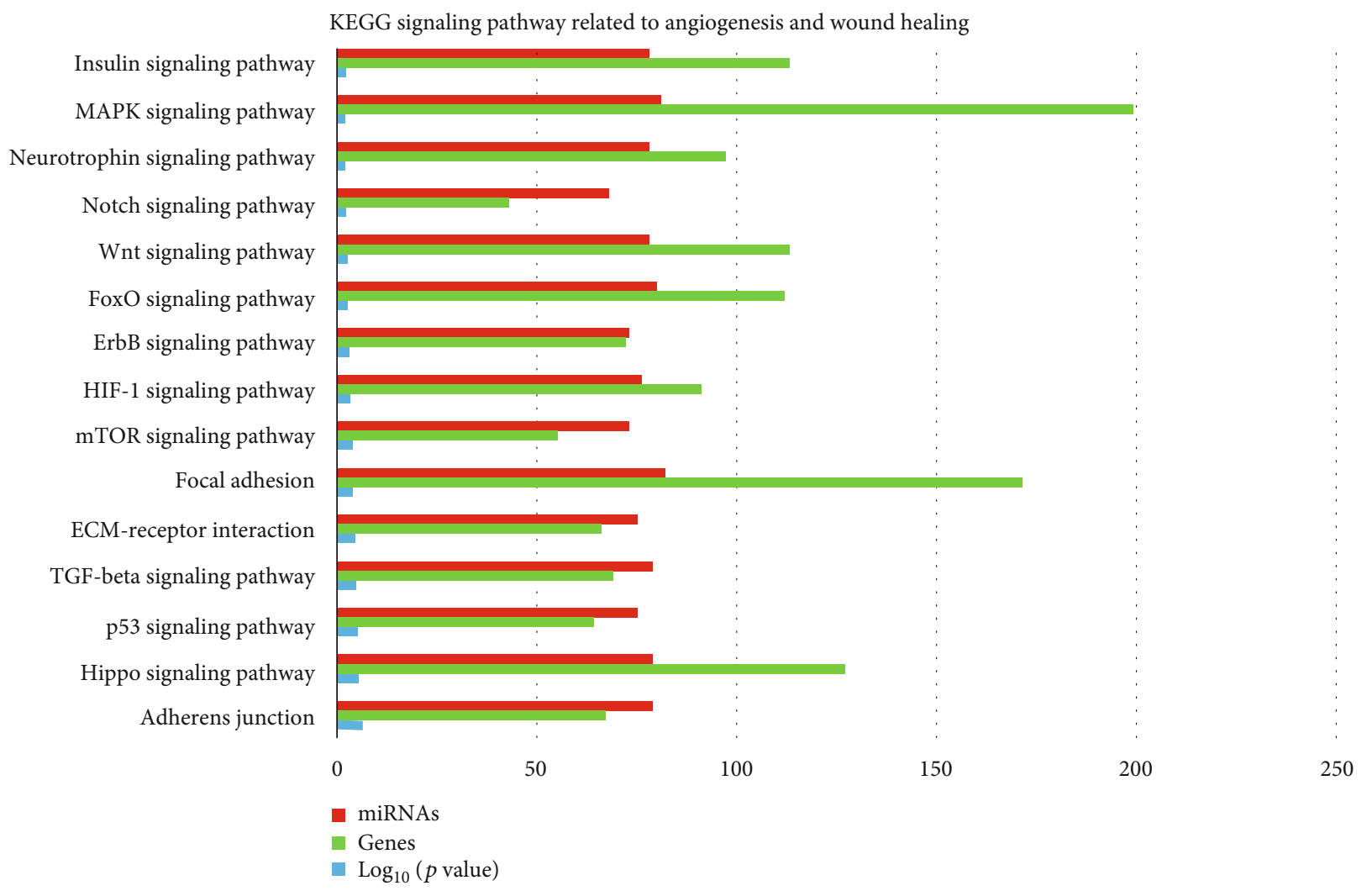

FIgURE 2: KEGG signaling pathways related to angiogenesis and wound healing obtained by screening out the 87 miRNAs considered significantly upregulated in fetal cell- vs. adult cell-derived EVs with the DIANA-miRPath v.3 software. The figure shows $\log _{10}(p$ value) (blue bars) associated with the number of miRNAs (red bars) targeting specific genes (green bars) within each pathway.

cyclin-dependent kinase inhibitor 1 (CDKN1A), cell division protein kinase 6 (CDK6), TNF receptor superfamily member 10b (TNFRSF10B), and mouse double minute 2 homolog (MDM2) (S3); 73 miRNAs enriched in the PIK3/Akt signaling pathway with putative target genes THBS1, FN1, CCND2, CCND1, CDKN1A, CDK6, MDM2, insulin-like growth factor 1 receptor (IGF1R), and MCL1 (S3); 64 miRNAs enriched in the FoxO signaling pathway with the target genes CCND2, CCND1, MDM2, and IGF1R (S3).

3.3. Validation of the In Silico Analysis by Western Blot. The amount of THBS1 protein in fibroblasts treated for 72 hours with $10 \mu \mathrm{g} / \mathrm{ml}$ of fetal-derived EVs was higher than the amount of THBS1 protein in both untreated fibroblasts (Figure 4(a)) and the earlier time points of treatment (24 and 48 hours, data not shown). The amount of THBS1 protein in fibroblasts following a 72-hour treatment with fetalderived EVs was approximately 4-fold higher than the amount of THBS1 protein in untreated fibroblasts at the same time point (Figure 4(b)).

3.4. EV/CM-Induced Mesh-Like Organization of HUVECs In Vitro. HUVECs cultured in culture medium supplemented with 100,50 , or $10 \mu \mathrm{g} / \mathrm{ml}$ of fetal dermal cell-derived EVs achieved the "complete mesh-like structures" pattern (maximum score 5) 8 hours after plating on Matrigel (Figure 5(a) obtained with $10 \mu \mathrm{g} / \mathrm{ml} \mathrm{EVs),} \mathrm{while} \mathrm{only} \mathrm{achieved} \mathrm{the}$ "sprouting of new capillary tubes" pattern (score 3) when cultured in the presence of $10 \mu \mathrm{g} / \mathrm{ml}$ of adult dermal cellderived EVs (Figure 5(b); Supplemental Material S4). The score 5 was achieved faster (approximately 3 hours) when cells were cultured in serum-free CM than in EVs of fetal dermal cells (Figure 5(c)). Interestingly, culturing HUVECs in EV-depleted CM only determined the achievement of score 3 (Figure 5(d)). Negative control HUVECs cultured in the absence of EVs maintained the "individual cells" pattern (score 0) for all the duration of the experiment (Figure 5(e)) (Table 3). Lower doses of fetal dermal cellderived EVs $(\leq 5 \mu \mathrm{g} / \mathrm{ml})$ were ineffective in inducing formation of mesh-like structures (data not shown). The results were confirmed by angiogenesis parameters quantified on images $(n=4$ for treatment with fetal-derived EVs; $n=3$ for the other treatments). In the case of HUVECs cultured in the presence of $10 \mu \mathrm{g} / \mathrm{ml}$ of adult dermal cell-derived EVs, histograms were lower to those of HUVECs cultured in the presence of fetal cell-derived EVs, but differences were not statistically significant, probably due to the high $\mathrm{SD}$ values. Data were expressed as total mesh area (Figure 6(a)), number of junctions (Figure 6(b)), number of nodes (Figure 6(c)), number of segments (Figure 6(d)), and total length of segments (Figure $6(\mathrm{e}))\left({ }^{*} p\right.$ value $\leq 0.05$; ${ }^{* *} p$ value $\left.\leq 0.001\right)$.

3.5. EV/CM-Induced Migration of Fibroblasts In Vitro. Fibroblasts in the presence of 100,50 , or $10 \mu \mathrm{g} / \mathrm{ml}$ of fetal dermal cell-derived EVs (green, red, and dark blue curves, 


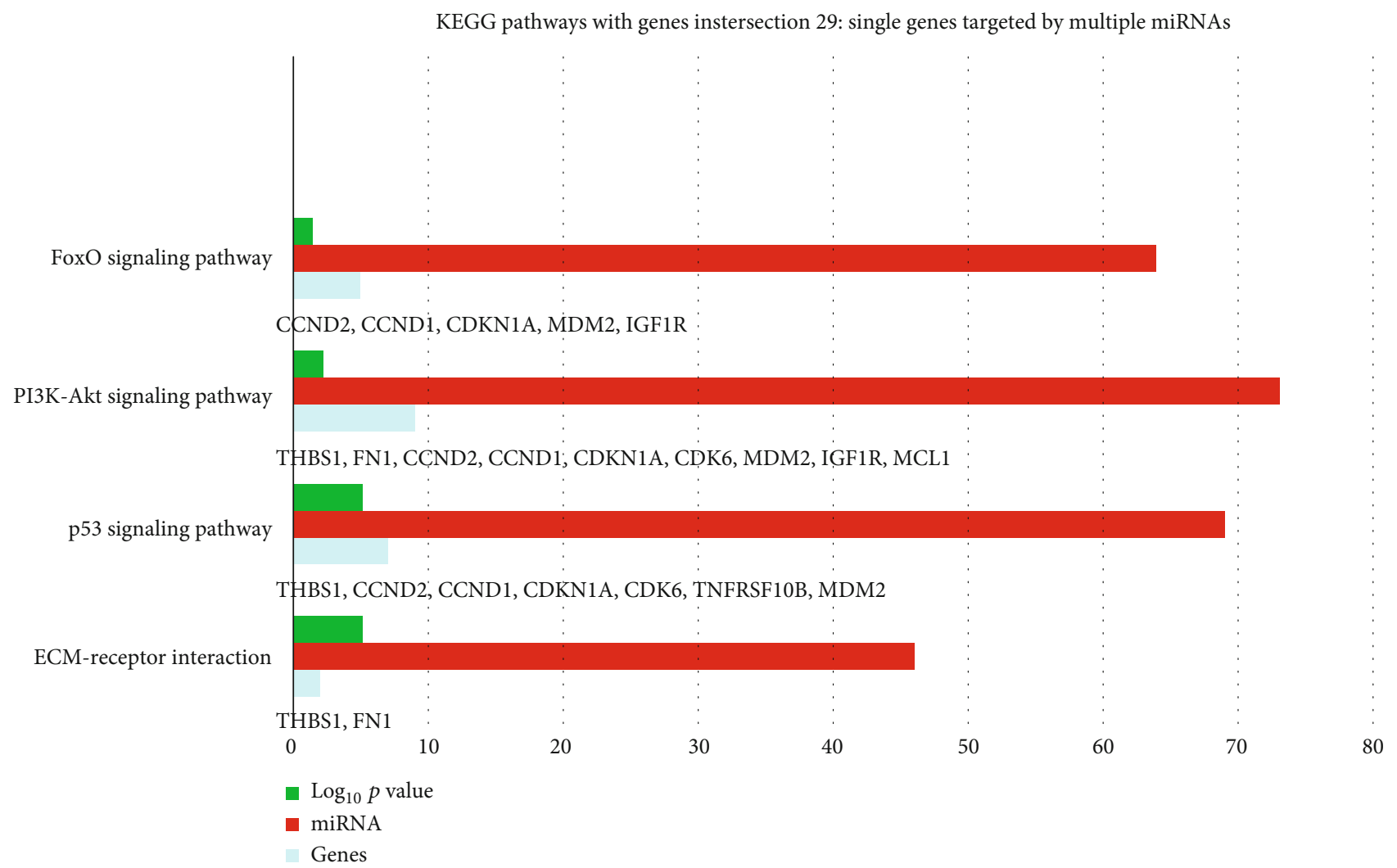

FIGURE 3: KEGG signaling pathways related to angiogenesis and wound healing obtained with genes intersection 29 to show putative genes targeted by multiple miRNAs within each pathway. DIANA tool was performed with the 87 miRNAs considered significantly upregulated in fetal dermal cell-derived EVs compared to adult dermal cell-derived EVs.
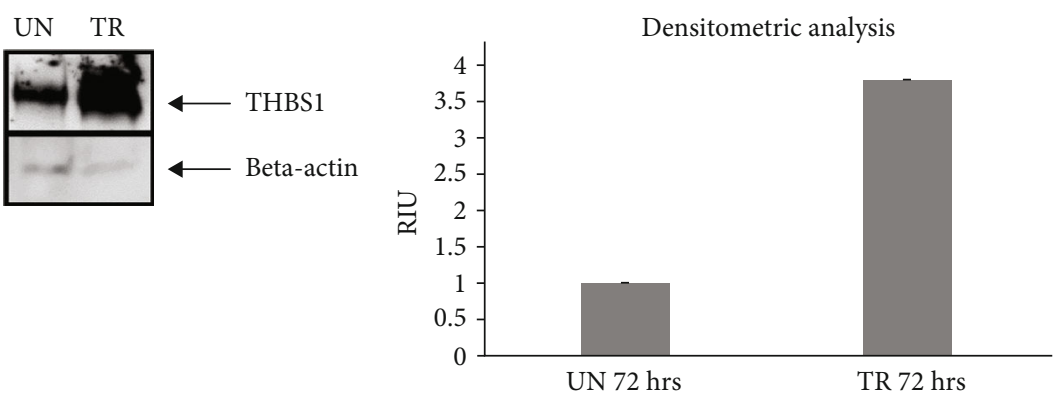

(a)

(b)

FIGURE 4: Validation of the in silico data. (a) Representative Western blot of THBS1 protein in total protein extracts of fibroblasts, untreated or treated with $10 \mu \mathrm{g} / \mathrm{ml}$ of fetal-derived EVs for 72 hours. Beta-actin was used as internal loading control. (b) Densitometric analysis of the 72-hour time point. UN: untreated; TR: treated; THBS1: thrombospondin 1; EV: extracellular vesicle; RIU: relative intensity unit.

respectively) migrated toward the lower chamber (containing culture medium $0.5 \%$ FBS as chemoattractant) with similar CI values. A lower concentration of EVs $(5 \mu \mathrm{g} / \mathrm{ml})$ (light blue curve) resulted in the absence of migration, and CI values similar to those of negative control fibroblasts seeded in the absence of EVs (pink curve) (Figure 7). The CI values of cell migration induced by $10 \mu \mathrm{g} / \mathrm{ml}$ of adult-derived EVs were similar to those induced by EVs of fetal origin (dark blue and orange curves, respectively) (data not shown).

3.6. Amount of Growth Factors and Chemokines in EVDepleted CM. The levels of growth factors and chemokines in EV-depleted CM were similar to the levels in whole fetal dermal cell CM. The growth factor detected with the highest amount was VEGF-A, while the chemokine detected with the highest amount was SDF-1-alpha (Table 4).

3.7. Cellular Uptake of EVs. Labeling of fetal dermal cellderived EVs with CSFE was successfully verified by flow cytometry. We clearly identified a discrete population of fluorescent particles in the range of small EVs compared to control, unlabeled EVs (Figure 8(a)). The fluorescent signal of CSFE-labeled EVs was visualized into the cytosol starting from 4 hours of incubation (Figure $8(\mathrm{~b})$ ), while at later time 


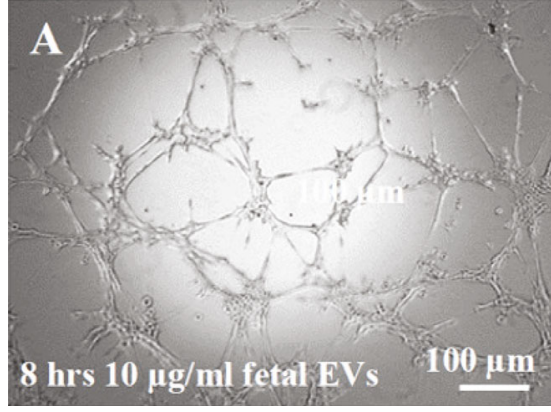

(a)

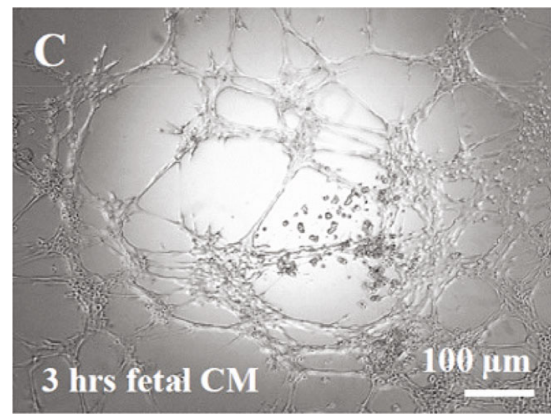

(c)

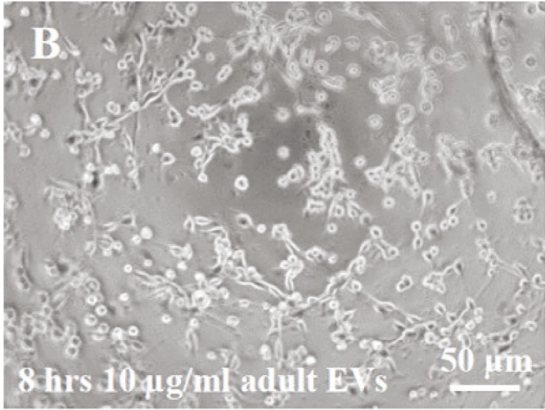

(b)

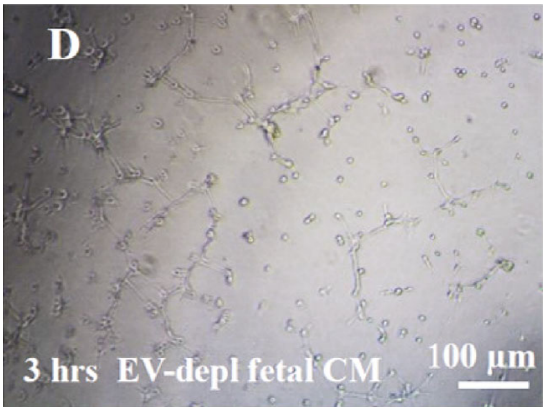

(d)

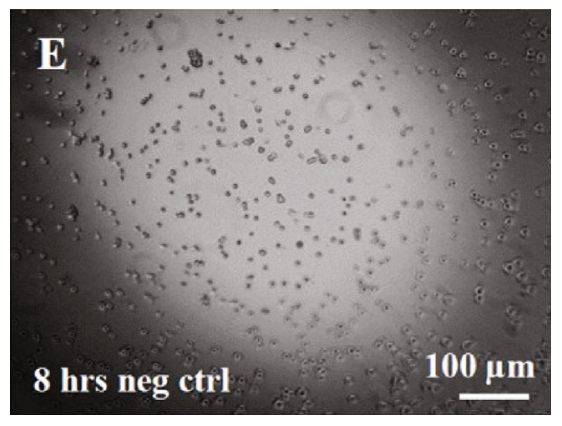

(e)

FIGURE 5: Effect of EVs on formation of mesh-like structures of HUVECs in vitro. (a) HUVECs in culture medium supplemented with $10 \mu \mathrm{g} / \mathrm{ml}$ of fetal dermal cell-derived EVs 8 hours after plating on Matrigel. (b) HUVECs in culture medium supplemented with $10 \mu \mathrm{g} / \mathrm{ml}$ of adult dermal cell-derived EVs 8 hours after plating. (c) HUVECs in fetal dermal cell-derived CM 3 hours after plating. (d) HUVECs in EV-depleted CM of fetal dermal cells 3 hours after plating. Negative control HUVECs in serum-free culture medium 8 hours after plating. Scale bars: $100 \mu \mathrm{m}$ (a, c, d, e) and $50 \mu \mathrm{m}$ (b). EV: extracellular vesicles; CM: conditioned medium; depl: depleted; neg. ctrl: negative control. The results shown are representative of four independent experiments.

TABLE 3: Numerical value assigned to each pattern associated with the degree of in vitro angiogenesis. A representative sample for each condition is shown, corresponding to Figure 5.

\begin{tabular}{lcc}
\hline Sample & Pattern & Score \\
\hline Fetal EVs & Complete mesh-like structures & 5 \\
Adult EVs & Sprouting of new capillary tubes & 3 \\
Fetal CM & Complete mesh-like structures & 5 \\
EV-depleted fetal CM & Sprouting of new capillary tubes & 3 \\
Negative control & Individual cells, well separated & 0 \\
\hline
\end{tabular}

EV: extracellular vesicles; CM: conditioned medium. points ( 8 hours of incubation; Figure $8(\mathrm{c})$ ), the signal was mainly detected in the perinuclear region of target cells. No differences were found when using targeted HUVECs or fibroblasts (data not shown).

\section{Discussion}

As a continuation of the previous study [12] and in search for the molecules contributing to functional activity of secretome, we herein focused on isolation and characterization of EVs from secretome of human fetal dermal cells. We used equal numbers of cultured cells and collected equal volumes of secretome at the same time, in the attempt to standardize the EV source. We followed the updated guidelines of the International Society for Extracellular Vesicles (ISEV), which 
Tot. meshes area

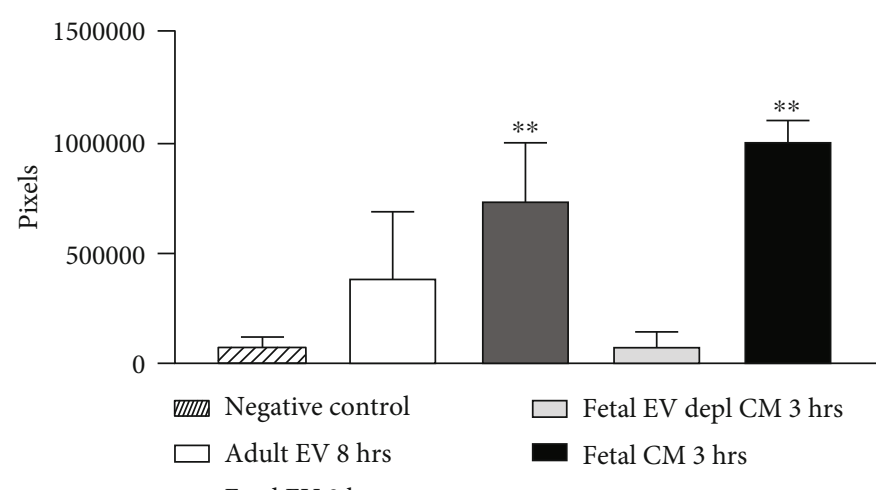

(a)

$\mathrm{Nb}$ nodes

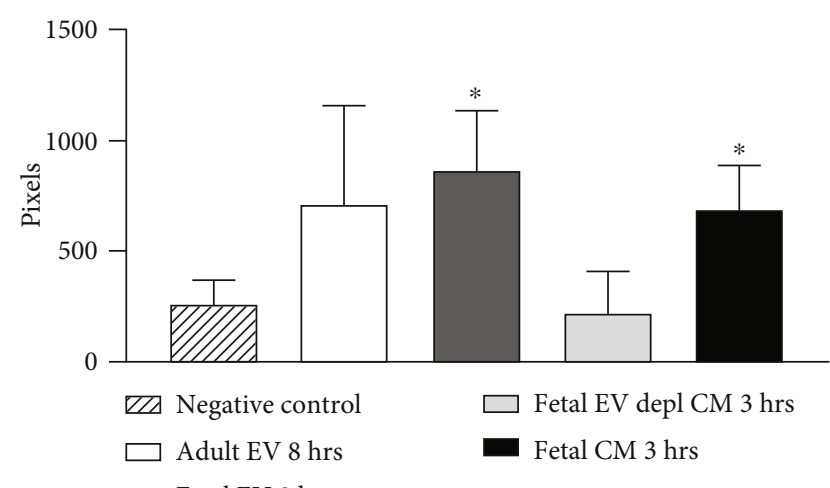

(c)
$\mathrm{Nb}$ junctions

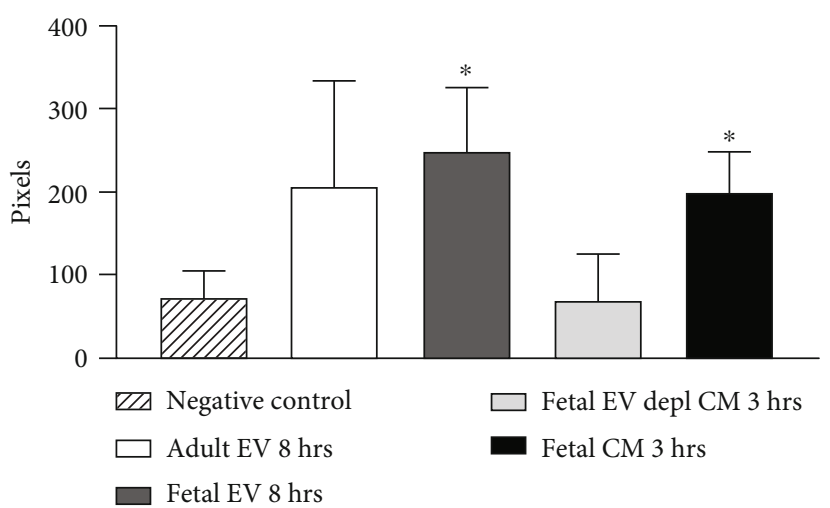

(b)

$\mathrm{Nb}$ segments

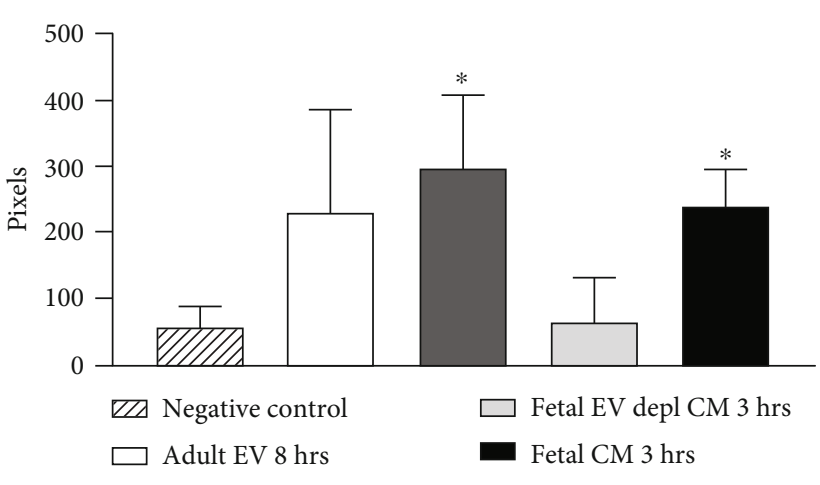

(d)

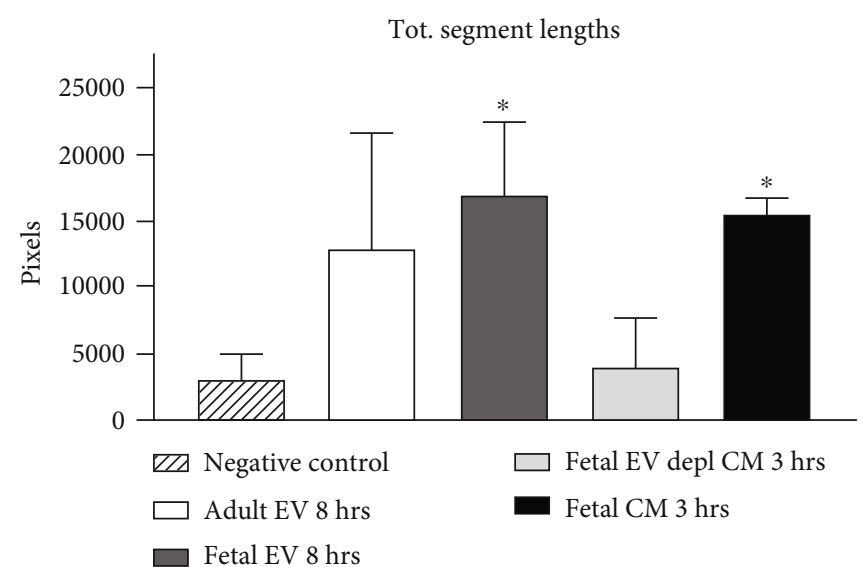

(e)

FIgURE 6: Angiogenic parameters quantified with the Angiogenesis Analyzer of ImageJ on images indicating (a) total mesh area, (b) number of junctions, (c) number of nodes, (d) number of segments, and (e) total segment length. $10 \mu \mathrm{g} / \mathrm{ml}$ of EVs was always used. The images corresponded to the 3-hour time point for treatments with $\mathrm{CM}$ and to the 8-hour time point for treatment with EVs and for negative controls. Plotted values (mean $\pm S D$ ) represent samples $(n=3$ for each condition, except $n=4$ for treatment with fetal dermal cell-derived EVs). ${ }^{*} p \leq 0.05 ;{ }^{* *} p \leq 0.001$. Differences not denoted with an asterisk are not significant. Tot: total; EV: extracellular vesicle; depl: depleted; CM: conditioned medium; $\mathrm{Nb}$ : number.

recommend to use the generic term "EVs" for particles naturally secreted by cells, whose characterization is mainly based on physical parameters, such as size and concentrations [24]. The NTA of pellet particles obtained by ultracentrifugation of secretome of both fetal and adult dermal cells revealed a size diameter of approximately $70 \mathrm{~nm}$, thus suggesting that we may have isolated "small EVs." In fact, the general characterization suggested by the ISEV discriminates EV subtypes 


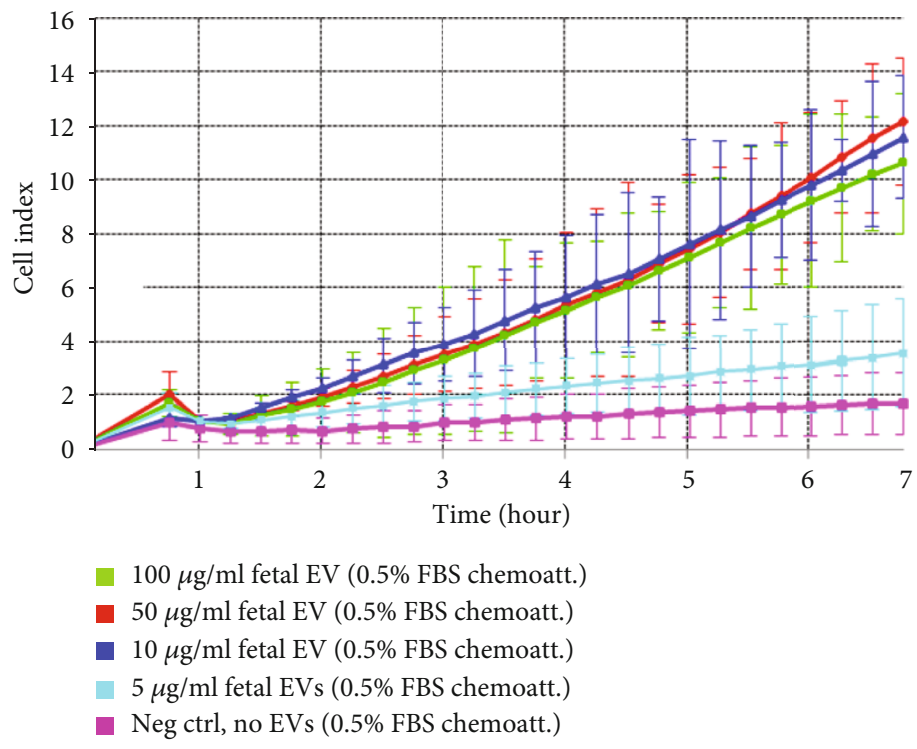

Figure 7: Effect of EVs on migration of fibroblasts in vitro. RTCA curves showing fibroblasts seeded in the presence of 100, 50, 10, and $5 \mu \mathrm{g} / \mathrm{ml}$ of fetal dermal cell-derived EVs. Culture medium containing a small amount of FBS (0.5\%) was used as chemoattractant. RTCA curve of negative control fibroblasts seeded without EVs is also shown. RTCA: real-time cell analyzer; EVs: extracellular vesicles; chemoatt: chemoattractant; FBS: fetal bovine serum; neg ctrl: negative control. The results shown are representative of six independent experiments.

TABle 4: Customized ProcartaPlex human growth factor and chemokine panel. Amount of soluble factors in EV-depleted vs. whole CM of fetal dermal cells.

\begin{tabular}{|c|c|c|c|}
\hline Soluble factor & Role in MSC-mediated wound healing & $\begin{array}{l}\text { EV-depleted } \mathrm{CM}\left(\mathrm{pg} / \mathrm{ml} / 10^{6}\right. \\
\text { cells } / 24 \mathrm{~h})\end{array}$ & $\begin{array}{l}\text { Whole } \mathrm{CM}\left(\mathrm{pg} / \mathrm{ml} / 10^{6}\right. \\
\text { cells } / 24 \mathrm{~h})\end{array}$ \\
\hline VEGF-A & Angiogenesis [86] & $6049 \pm 1603$ & $5899 \pm 618$ \\
\hline HGF & Epithelialization, neovascularization [87] & $1031 \pm 246$ & $1448 \pm 121$ \\
\hline $\begin{array}{l}\text { SDF-1 alpha } \\
(\text { CXCL-12) }\end{array}$ & Angiogenesis [88]; cell migration [89] & $6016 \pm 1860$ & $5983 \pm 231$ \\
\hline MCP-1 (CCL-2) & $\begin{array}{c}\text { Angiogenesis [1]; recruitment of neutrophils [90]; } \\
\text { remodeling [91] }\end{array}$ & $1771 \pm 795$ & $1233 \pm 54$ \\
\hline IL-8 & $\begin{array}{c}\text { Recruitment of neutrophils, epidermal cell migration, } \\
\text { angiogenesis [91] }\end{array}$ & $1546 \pm 293$ & $788 \pm 697$ \\
\hline $\begin{array}{l}\text { GRO-alpha } \\
\text { (CXCL-1) }\end{array}$ & Recruitment of neutrophils [91]; angiogenesis [1] & $907 \pm 328$ & $973 \pm 100$ \\
\hline
\end{tabular}

Plotted values (mean $\pm \mathrm{SD})$ represent EV-depleted CM $(n=10)$ compared to whole CM $(n=10)$. Differences not denoted with an asterisk are not significant. EV: extracellular vesicle; CM: conditioned medium.

in small EVs $(<200 \mathrm{~nm}$ size) and larger EVs [24]. Furthermore, the isolated EVs were positive for Rab5 and Alix, and CD63 while were negative for calnexin [24]. Since there is no a perfect quantification method, we followed the most common, which is based on total protein amounts in our dose-response studies [24].

Depletion of EVs by differential ultracentrifugation almost abrogated the in vitro proangiogenic effect of fetal dermal cell secretome. Since depletion of EVs only slightly reduced the efficiency of cell migration, we suggest that perhaps the amount of chemokines such as SDF-1 alpha and MCP-1 in EV-depleted secretome may be sufficient to ensure a migratory response. On the contrary, a VEGF-A concentration of approximately $5000 \mathrm{pg} / \mathrm{ml}$ in EV-depleted secretome could not be sufficient to ensure formation of mesh-like structures normally requiring higher doses of VEGF-A (e.g., $20000 \mathrm{pg} / \mathrm{ml}$ or more) [25]. Nevertheless, the multitude of factors contained in secretome is extremely difficult to establish which factor might be responsible for one activity or another.

According to the current version of the database Exocarta [26, 27], 9769 proteins, 1116 lipids, 3408 mRNAs, and 2838 miRNAs have been identified in EV/exosomes from several cell types and organisms. Research studies have often hypothesized that the transfer of miRNAs in particular will account for the understood EV-mediated effects [14]. miRNA-based therapy entered in clinical studies mainly for cancer treatments, while it is still in early stages for 

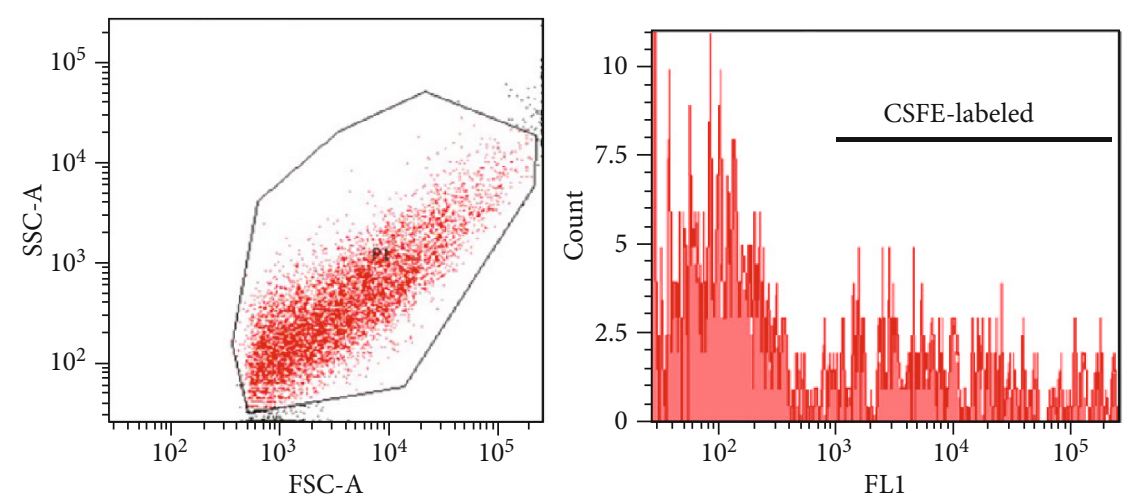

(a)

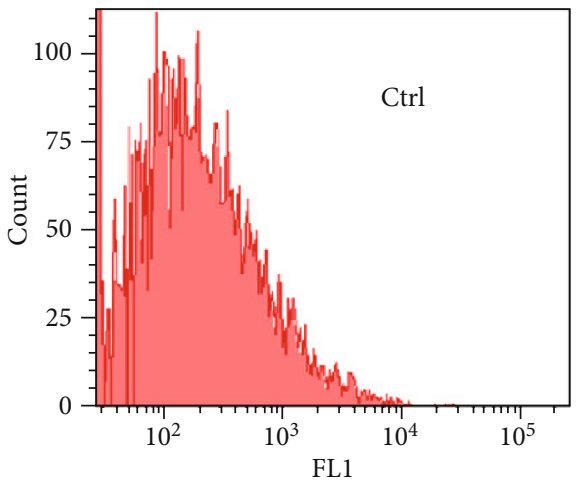

FL1

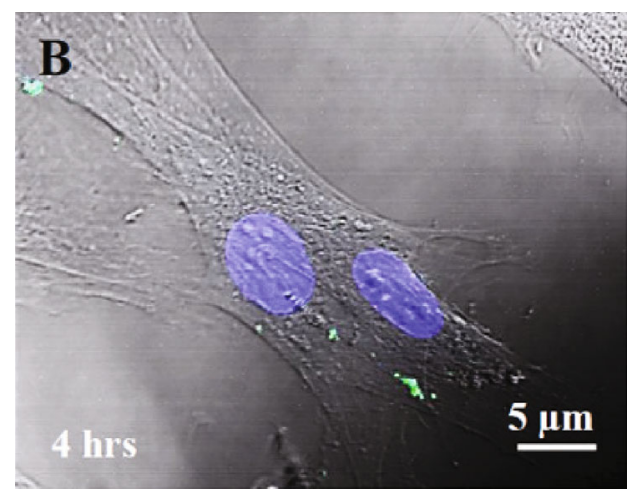

(b)

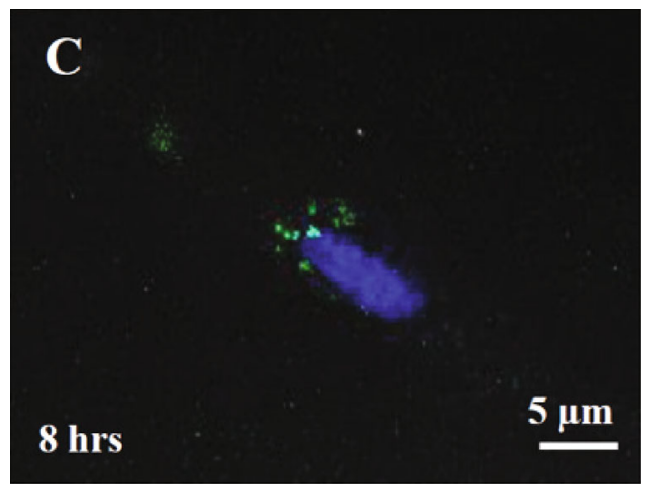

(c)

FIGURE 8: Internalization of CSFE-labeled EVs by targeted fibroblasts. (a) EVs analyzed by flow cytometry in a linear range for physical parameters FSC vs. SSC (forward scatter vs. side scatter) using Miltenyi beads as size marker. CSFE-labeled EVs and negative control, unlabeled EVs are also shown. Confocal images showing uptake of CSFE-labeled EVs by fibroblast target cells at 4- and 8-hour incubation times. (b) Bright field image merged with green (CSFE) and blue (DAPI) showing cytoplasmic localization of fluorescent signal at 4 hours of incubation. (c) Dual-channel confocal fluorescence showing cytoplasmic localization of fluorescent signal at 8 hours of incubation. The results shown are representative of three independent experiments. CSFE: carboxyfluorescein succinimidyl ester; EVs: extracellular vesicles; FL1: fluorescence 1 . Scale bar: $5 \mu \mathrm{m}$.

applications of regenerative medicine [28, 29]. However, emerging reports are available indicating the vast potential of miRNAs for the repair of several tissues including bone/cartilage muscle, cardiovascular tissue, neurological tissue, skin, and even in angiogenesis $[29,30]$. With respect to organ repair and angiogenesis, the involvement of miRNAs in different phases of wound healing has been documented [31, 32 ], and several proangiogenic miRNAs have been identified and validated $[33,34]$.

By analyzing the miRNA expression profile of dermal cell-derived EVs, we identified 87 miRNAs significantly upregulated in fetal- vs. adult-derived EVs, which included miRNAs validated in angiogenesis such as let-7b-5p, let-7g5p, miRNA-10a, -15b, -16-5p, members of the cluster 17-92 (-17-5p, -19a-3p, -19b-3p, -20a-5p, -92a-3p), -21-5p, members of the cluster $23-27(-24-3 p,-27 b-3 p),-31-3 p,-31-5 p$, $-132-3 \mathrm{p},-199 \mathrm{a}-3 \mathrm{p},-218-5 \mathrm{p},-221-3 \mathrm{p},-222-3 \mathrm{p}$, and $-320 \mathrm{a}$ $[29,34-40]$ (Table 1). Since the depletion of EVs from fetal dermal cell secretome impaired the in vitro tube formation, we suggest that the proangiogenic effect of fetal dermal cell secretome reported in our previous study [12] could largely depend on an EV-mediated transfer of these miRNAs. Inter- estingly, significantly upregulated miRNAs in fetal- vs. adult cell-derived EVs also included proregenerative miRNAs such as $-26 a$ [41], -29b [42, 43], -132 [44], -193b-3p [45], and $-199 a-3 p$ [46], which have been delivered in animal models to improve angiogenesis, bone and cartilage regeneration, cardiac regeneration, and for fibrosis treatment (Table 1).

According to KEGG analysis, 85 signaling pathways were detected as targets for the 87 miRNAs upregulated in fetalvs. adult-derived EVs. Each of the pathways was targeted by multiple miRNAs, and 15 of the 85 pathways were associated with angiogenesis and wound healing. These 15 pathways included adherent junction [47], HIPPO [48-51], p53 [52], TGF-beta [53, 54], ECM-receptor interaction [55], focal adhesion [56], mTOR (interconnected to PI3K-Akt) [5759], HIF-1 [60], ErbB [61], FoxO (upstream in the activation of TGF-beta and PI3k-Akt), Wnt [62], Notch [63-66], neurotrophin [67], MAPK [68], and insulin (upstream to mTOR) signaling pathways. Of particular interest was the HIPPO signaling, whose role in regulating regeneration of organs such as the intestine, liver, heart, nervous system, and skin is well documented. By setting genes intersection option (29), 10 putative target genes (THBS1, FN1, CCND1, 
CCND2, CDKN1A, CDK6, TNFRSF10B, MDM2, IGF1R, and MCL1) associated with 4 of the 15 signaling pathways (ECM-receptor interaction, PI3K/Akt, p53, and FoxO) were obtained and predicted as targets for our miRNAs. Among the putative target genes, we focused on THBS1 to validate the in silico analysis. THBS1 is a multifunctional extracellular matrix glycoprotein produced by several cell types, facilitating tissue repair in different healing models [69-71]. Western blot analysis showed a significant increase of THBS1 protein amounts (approximately 4 -fold) in fibroblasts treated for 72 hours with fetal dermal-derived EVs against untreated fibroblasts.

Both freshly isolated and frozen EVs were tested in cellbased assays of angiogenesis and cell migration, thus showing no differences in their performances. This observation was in agreement with a previous report showing that the storage in the absence of cryoprotectant at $-20^{\circ} \mathrm{C}$ did not affect the biochemical activity of EVs [72]. While EVs from both cell types stimulated cell migration with a similar efficacy, fetal dermal cell-derived EVs were far more effective than adult dermal cell-derived EVs in inducing formation of mesh-like structures. Even if this result was not statistically significant, the slide in Supplemental Material S4 clearly shows this difference. Overall, we observed a delay in EV-induced cellular responses compared to secretome/CM-induced cellular responses. Since the delay was independent from the used EV concentrations (e.g., either 100 or $10 \mu \mathrm{g} / \mathrm{ml}$ ), we suggest that the delay could be due to the dynamic of EV internalization by target cells.

In view of the promising prospective of miRNA-based therapeutics, the research is dedicated in solving some challenges in order to make it more translationally valuable. These challenges include the off-target effects of miRNA or their low internalization by target cells making their delivery difficult [73]. Typically, miRNAs for therapeutics have been delivered by direct injection, viral vectors, or coupled to scaffolds [74]. A number of studies indicate that EVs may exert their effect via horizontal transfer of their cargo [14]. Therefore, EVs could serve as a vehicle to successfully deliver miRNAs of interest to several therapeutic applications [75]. Confocal microscope observations of a punctuated green fluorescent pattern inside target cells suggest successful internalization of CSFE-labeled EVs. The signal was visualized in the cytosol of both HUVECs and fibroblasts at not earlier than 4 hours of incubation, and in the perinuclear region at later time points (from 8 hours of incubation). To conclude, the proangiogenic features of secretome of human fetal dermal cells appear largely related to the presence of small EVs. Although there is much to be learned in the field of EV research, the unique properties of these particles clearly represent a new therapeutic opportunity for tissue regeneration $[15,76]$, since it could offer a number of advantages over traditional cell transplantation as a cell-free product. As with conventional drugs, EVs can be standardized and tested in terms of dose and biological activity. Furthermore, EVs can be produced in clinical grade, freeze, and easily delivered. Finally, EV-based therapy could overcome the challenge of a successful delivery of miRNA molecules in vivo [77].

\section{Data Availability}

The data concerning the NTA of EVs, the heat map graph, the figures and graphs of in vitro angiogenesis, the curves of cell migration, the flow cytometry graphs of CSFElabeled EVs, and the uptake of EVs used to support the findings of this study are included within the article. The miRNA data used to support the findings of this study are included as a table within the articles, but also in supplementary information file S1 The KEGG data used to support the findings of this study are included within the article (as graphs), and also in supplementary information files S2 and S3.

\section{Conflicts of Interest}

The authors declare no conflicts of interest.

\section{Acknowledgments}

We wish to thank the Gynecology Unit of Ospedale Civico (Palermo, Italy) for providing the fetal skin biopsies. We thank Prof. Marcello Monti and Dr. Stefania Motta of Istituto Humanitas (Rozzano, Italy) for providing the adult skin biopsies. We also thank Dr. Vitale Miceli of IRCCSISMETT (Palermo, Italy) for providing additional EVs for biochemical characterization. This work was supported by the Italian Ministry of Education, University and Research (MIUR) (NOP for Research and Competitiveness 20072013, IRMI (CTN01_00177_888744)).

\section{Supplementary Materials}

S1 (excel file): list of significantly upregulated miRNAs in fetal vs. adult EVs; a list of all analyzed miRNAs is also included. S2 (excel file): complete list of the KEGG signaling pathways; list of the KEGG signaling pathways associated with angiogenesis and wound healing. S3 (excel file): complete list of the KEGG signaling pathways obtained with genes intersection 29, including putative target genes. S4 (power point slide): pictures of HUVECs treated with fetalderived EVs $(n=4)$ and adult-derived EVs $(n=3)$. Each picture represents an independent experiment. (Supplementary Materials)

\section{References}

[1] J. Folkman, "Angiogenesis in cancer, vascular, rheumatoid and other disease," Nature Medicine, vol. 1, no. 1, pp. 27-30, 1995.

[2] G. P. Lasala, J. A. Silva, and J. J. Minguell, "Therapeutic angiogenesis in patients with severe limb ischemia by transplantation of a combination stem cell product," The Journal of Thoracic and Cardiovascular Surgery, vol. 144, no. 2, pp. 377-382, 2012.

[3] E. Eggenhofer, V. Benseler, A. Kroemer et al., "Mesenchymal stem cells are short-lived and do not migrate beyond the lungs after intravenous infusion," Frontiers in Immunology, vol. 3, p. 297, 2012.

[4] M. E. Fung and B. Thébaud, "Stem cell-based therapy for neonatal lung disease: it is in the juice," Pediatric Research, vol. 75, no. 1, pp. 2-7, 2014. 
[5] J. A. Pawitan, "Prospect of stem cell conditioned medium in regenerative medicine," BioMed Research International, vol. 2014, Article ID 965849, 14 pages, 2014.

[6] C. Tran and M. S. Damaser, "Stem cells as drug delivery methods: application of stem cell secretome for regeneration," Advanced Drug Delivery Reviews, vol. 82-83, pp. 1-11, 2015.

[7] N. Hirt-Burri, A.-A. Ramelet, W. Raffoul et al., "Biologicals and fetal cell therapy for wound and scar management," ISRN Dermatology, vol. 2011, Article ID 549870, 16 pages, 2011.

[8] A. A. Ramelet, N. Hirt-Burri, W. Raffoul et al., "Chronic wound healing by fetal cell therapy may be explained by differential gene profiling observed in fetal versus old skin cells," Experimental Gerontology, vol. 44, no. 3, pp. 208-218, 2009.

[9] A. S. De Buys Roessingh, J. Hohlfeld, C. Scaletta et al., "Development, characterization, and use of a fetal skin cell bank for tissue engineering in wound healing," Cell Transplantation, vol. 15, no. 8-9, pp. 823-834, 2006.

[10] J. Hohlfeld, A. De Buys Roessingh, N. Hirt-Burri et al., "Tissue engineered fetal skin constructs for paediatric burns," The Lancet, vol. 366, no. 9488, pp. 840-842, 2005.

[11] C. M. Chinnici, G. Amico, M. Monti et al., "Isolation and characterization of multipotent cells from human fetal dermis," Cell Transplantation, vol. 23, no. 10, pp. 1169-1185, 2014.

[12] M. Gaetani, C. M. Chinnici, A. P. Carreca, C. Di Pasquale, G. Amico, and P. G. Conaldi, "Unbiased and quantitative proteomics reveals highly increased angiogenesis induction by the secretome of mesenchymal stromal cells isolated from fetal rather than adult skin," Journal of Tissue Engineering and Regenerative Medicine, vol. 12, no. 2, pp. e949-e961, 2018.

[13] G. Raposo and W. Stoorvogel, "Extracellular vesicles: exosomes, microvesicles, and friends," The Journal of Cell Biology, vol. 200, no. 4, pp. 373-383, 2013.

[14] L. A. Mulcahy, R. C. Pink, and D. R. F. Carter, "Routes and mechanisms of extracellular vesicle uptake," Journal of Extracellular Vesicles, vol. 3, no. 1, p. 3, 2014.

[15] H. Jing, X. He, and J. Zheng, "Exosomes and regenerative medicine: state of the art and perspectives," Translational Research, vol. 196, pp. 1-16, 2018.

[16] T. Katsuda and T. Ochiya, "Molecular signatures of mesenchymal stem cell-derived extracellular vesicle-mediated tissue repair," Stem Cell Research \& Therapy, vol. 6, no. 1, p. 212, 2015.

[17] F. Marqués-García and M. Isidoro-García, "Protocols for exosome isolation and RNA profiling," Methods in Molecular Biology, vol. 1434, pp. 153-167, 2016.

[18] C. M. Chinnici, G. Pietrosi, G. Iannolo et al., "Mesenchymal stromal cells isolated from human fetal liver release soluble factors with a potential role in liver tissue repair," Differentiation, vol. 105, pp. 14-26, 2019.

[19] R. A. Dragovic, C. Gardiner, A. S. Brooks et al., "Sizing and phenotyping of cellular vesicles using nanoparticle tracking analysis," Nanomedicine: Nanotechnology, Biology and Medicine, vol. 7, no. 6, pp. 780-788, 2011.

[20] I. S. Vlachos, N. Kostoulas, T. Vergoulis et al., "DIANA miRPath v.2.0: investigating the combinatorial effect of microRNAs in pathways," Nucleic Acids Research, vol. 40, no. W1, pp. W498-W504, 2012.

[21] R. Limame, A. Wouters, B. Pauwels et al., "Comparative analysis of dynamic cell viability, migration and invasion assessments by novel real-time technology and classic endpoint assays," PLoS One, vol. 7, no. 10, article e46536, 2012.
[22] G. Iannolo, M. R. Sciuto, G. M. Raffa, M. Pilato, and P. G. Conaldi, "MiR34 inhibition induces human heart progenitor proliferation," Cell Death \& Disease, vol. 9, no. 3, p. 368, 2018.

[23] R. B. Dessau and C. B. Pipper, “"R”- project for statistical computing," Ugeskrift for Laeger, vol. 170, no. 5, pp. 328-330, 2008.

[24] C. Théry, K. W. Witwer, E. Aikawa et al., "Minimal information for studies of extracellular vesicles 2018 (MISEV2018): a position statement of the International Society for Extracellular Vesicles and Update of the MISEV2014 Guidelines," Journal of Extracellular Vesicles, vol. 7, no. 1, 2018.

[25] A. Taktak-BenAmar, M. Morjen, H. Ben Mabrouk et al., "Expression, purification and functionality of bioactive recombinant human vascular endothelial growth factor VEGF165 in E. coli," AMB Express, vol. 7, no. 1, p. 33, 2017.

[26] S. Mathivanan, C. J. Fahner, G. E. Reid, and R. J. Simpson, "ExoCarta 2012: database of exosomal proteins, RNA and lipids," Nucleic Acids Research, vol. 40, no. D1, pp. D1241D1244, 2011.

[27] http://www.exocarta.org..

[28] A. Christopher, R. Kaur, G. Kaur, A. Kaur, V. Gupta, and P. Bansal, "MicroRNA therapeutics: discovering novel targets and developing specific therapy," Perspectives in Clinical Research, vol. 7, no. 2, pp. 68-74, 2016.

[29] C. M. Curtin, I. M. Castaño, and F. J. O’Brien, “Scaffold-based microRNA therapies in regenerative medicine and cancer," Advanced Healthcare Materials, vol. 7, no. 1, 2018.

[30] C. K. Sen and S. Ghatak, "MiRNA control of tissue repair and regeneration," The American Journal of Pathology, vol. 185, no. 10, pp. 2629-2640, 2015.

[31] J. Banerjee and C. K. Sen, "MicroRNAs in skin and wound healing," Methods in Molecular Biology, vol. 936, no. 10, pp. 343-356, 2013.

[32] T. Wang, Y. Feng, H. Sun et al., "MiR-21 regulates skin wound healing by targeting multiple aspects of the healing process," The American Journal of Pathology, vol. 181, no. 6, pp. 19111920, 2012.

[33] A. Caporali and C. Emanueli, "MicroRNA regulation in angiogenesis," Vascular Pharmacology, vol. 55, no. 4, pp. 79-86, 2011.

[34] S. Landskroner-Eiger, I. Moneke, and W. C. Sessa, "MiRNAs as modulators of angiogenesis," Cold Spring Harbor Perspectives in Medicine, vol. 3, no. 2, 2013.

[35] G. Bridge, R. Monteiro, S. Henderson et al., "The microRNA30 family targets DLL4 to modulate endothelial cell behavior during angiogenesis," Blood, vol. 120, no. 25, pp. 5063-5072, 2012.

[36] Z. Hua, Q. Lv, W. Ye et al., "MiRNA-directed regulation of VEGF and other angiogenic factors under hypoxia," PLoS One, vol. 1, no. 1, p. e116, 2006.

[37] N. M. Kane, L. Howard, B. Descamps et al., "Role of microRNAs 99b, 181a, and 181b in the differentiation of human embryonic stem cells to vascular endothelial cells," Stem Cells, vol. 30, no. 4, pp. 643-654, 2012.

[38] Y. Suárez and W. C. Sessa, "MicroRNAs as novel regulators of angiogenesis," Circulation Research, vol. 104, no. 4, pp. 442454, 2009.

[39] S. Wang and E. N. Olson, "AngiomiRs-key regulators of angiogenesis," Current Opinion in Genetics \& Development, vol. 19, no. 3, pp. 205-211, 2009.

[40] Q. Zhou, R. Gallagher, R. Ufret-Vincenty, X. Li, E. N. Olson, and S. Wang, "Regulation of angiogenesis and choroidal 
neovascularization by members of microRNA-23 27 24 clusters," Proceedings of the National Academy of Sciences of the United States of America, vol. 108, no. 20, pp. 82878292, 2011.

[41] Y. Li, L. Fan, S. Liu et al., "The promotion of bone regeneration through positive regulation of angiogenic-osteogenic coupling using microRNA-26a," Biomaterials, vol. 34, no. 21, pp. 50485058, 2013.

[42] M. Monaghan, S. Browne, K. Schenke-Layland, and A. Pandit, "A collagen-based scaffold delivering exogenous microRNA29B to modulate extracellular matrix remodeling," Molecular Therapy, vol. 22, no. 4, pp. 786-796, 2014.

[43] E. Van Rooij, L. B. Sutherland, J. E. Thatcher et al., "Dysregulation of microRNAs after myocardial infarction reveals a role of MiR-29 in cardiac fibrosis," Proceedings of the National Academy of Sciences of the United States of America, vol. 105, no. 35, pp. 13027-13032, 2008.

[44] T. Ma, Y. Chen, Y. Chen et al., "MicroRNA-132, delivered by mesenchymal stem cell-derived exosomes, promote angiogenesis in myocardial infarction," Stem Cells International, vol. 2018, Article ID 3290372, 11 pages, 2018.

[45] F. Meng, Z. Li, Z. Zhang et al., "MicroRNA-193b-3p regulates chondrogenesis and chondrocyte metabolism by targeting HDAC3," Theranostics, vol. 8, no. 10, pp. 2862-2883, 2018.

[46] P. Lesizza, G. Prosdocimo, V. Martinelli, G. Sinagra, S. Zacchigna, and M. Giacca, "Single-dose intracardiac injection of pro-regenerative microRNAs improves cardiac function after myocardial infarction," Circulation Research, vol. 120, no. 8, pp. 1298-1304, 2017.

[47] G. Fenteany, P. A. Janmey, and T. P. Stossel, "Signaling pathways and cell mechanics involved in wound closure by epithelial cell sheets," Current Biology, vol. 10, no. 14, pp. 831-838, 2000.

[48] W. C. Juan and W. Hong, "Targeting the Hippo signaling pathway for tissue regeneration and cancer therapy," Genes, vol. 7, no. 9, p. 55, 2016.

[49] M. J. Lee, M. R. Byun, M. Furutani-Seiki, J. H. Hong, and H. S. Jung, "YAP and TAZ regulate skin wound healing," The Journal of Investigative Dermatology, vol. 134, no. 2, pp. 518-525, 2014.

[50] Y. Wang, A. Yu, and F. X. Yu, "The Hippo pathway in tissue homeostasis and regeneration," Protein \& Cell, vol. 8, no. 5, pp. 349-359, 2017.

[51] B. Zhao, K. Tumaneng, and K. L. Guan, “The Hippo pathway in organ size control, tissue regeneration and stem cell selfrenewal," Nature Cell Biology, vol. 13, no. 8, pp. 877-883, 2011.

[52] M. Farhang Ghahremani, S. Goossens, D. Nittner et al., "P53 promotes VEGF expression and angiogenesis in the absence of an intact P21-Rb pathway," Cell Death and Differentiation, vol. 20, no. 7, pp. 888-897, 2013.

[53] K. W. Finnson, P. R. Arany, and A. Philip, “Transforming growth factor beta signaling in cutaneous wound healing: lessons learned from animal studies," Advances in Wound Care, vol. 2, no. 5, pp. 225-237, 2013.

[54] H. Ramirez, S. B. Patel, and I. Pastar, "The role of TGF $\beta$ signaling in wound epithelialization," Advances in Wound Care, vol. 3, no. 7, pp. 482-491, 2014.

[55] P. Olczyk, Ł. Mencner, and K. Komosinska-Vassev, "The role of the extracellular matrix components in cutaneous wound healing," BioMed Research International, vol. 2014, Article ID 747584, 8 pages, 2014.
[56] X. Zhao and J. L. Guan, "Focal adhesion kinase and its signaling pathways in cell migration and angiogenesis," Advanced Drug Delivery Reviews, vol. 63, no. 8, pp. 610615, 2011.

[57] R. Castilho, C. Squarize, and J. Gutkind, "Exploiting PI3K/MTOR signaling to accelerate epithelial wound healing," Oral Diseases, vol. 19, no. 6, pp. 551-558, 2013.

[58] J. Chen, R. Crawford, C. Chen, and Y. Xiao, "The key regulatory roles of the PI3K/Akt signaling pathway in the functionalities of mesenchymal stem cells and applications in tissue regeneration," Tissue Engineering. Part B, Reviews, vol. 19, no. 6, pp. 516-528, 2013.

[59] J. Karar and A. Maity, "PI3K/AKT/MTOR pathway in angiogenesis," Frontiers in Molecular Neuroscience, vol. 4, 2011.

[60] W. X. Hong, M. S. Hu, M. Esquivel et al., "The role of hypoxiainducible factor in wound healing," Advances in Wound Care, vol. 3, no. 5, pp. 390-399, 2014.

[61] S. Pastore, F. Mascia, V. Mariani, and G. Girolomoni, "The epidermal growth factor receptor system in skin repair and inflammation," Journal of Investigative Dermatology, vol. 128, no. 6, pp. 1365-1374, 2008.

[62] J. L. Whyte, A. A. Smith, and J. A. Helms, "Wnt signaling and injury repair," Cold Spring Harbor Perspectives in Biology, vol. 4, no. 8, article a008078, 2012.

[63] M. E. Carlson, M. S. O'Connor, M. Hsu, and I. M. Conboy, "Notch signaling pathway and tissue engineering," Frontiers in Bioscience, vol. 12, no. 12, pp. 5143-5156, 2007.

[64] S. Chigurupati, T. V. Arumugam, T. G. Son et al., "Involvement of Notch signaling in wound healing," PLoS One, vol. 2, no. 11, p. e1167, 2007.

[65] Q. S. Ran, Y. H. Yu, X. H. Fu, and Y. C. Wen, "Activation of the Notch signaling pathway promotes neurovascular repair after traumatic brain injury," Neural Regeneration Research, vol. 10, no. 8, pp. 1258-1264, 2015.

[66] A. Raya, C. M. Koth, D. Büscher et al., "Activation of Notch signaling pathway precedes heart regeneration in zebrafish," Proceedings of the National Academy of Sciences of the United States of America, vol. 100, Supplement 1, pp. 11889-11895, 2003.

[67] R. Kraemer and B. L. Hempstead, "Neurotrophins: novel mediators of angiogenesis," Frontiers in Bioscience, vol. 8, no. 6, pp. s1181-s1186, 2003.

[68] M. Deng, W.-L. Chen, A. Takatori et al., "A role for the mitogen-activated protein kinase kinase kinase 1 in epithelial wound healing," Molecular Biology of the Cell, vol. 17, no. 8, pp. 3446-3455, 2006.

[69] L. A. DiPietro, N. N. Nissen, R. L. Gamelli, A. E. Koch, J. M. Pyle, and P. J. Polverini, "Thrombospondin 1 synthesis and function in wound repair," The American Journal of Pathology, vol. 148, no. 6, pp. 1851-1860, 1996.

[70] A. Agah, T. R. Kyriakides, J. Lawler, and P. Bornstein, "The lack of thrombospondin-1 (TSP1) dictates the course of wound healing in double-TSP1/TSP2-null mice," The American Journal of Pathology, vol. 161, no. 3, pp. 831-839, 2002.

[71] K. Uno, M. Kuroki, H. Hayashi, H. Uchida, M. Kuroki, and K. Oshima, "Impairment of thrombospondin-1 expression during epithelial wound healing in corneas of vitamin Adeficient mice," Histology and Histopathology, vol. 20, no. 2, pp. 493-499, 2005.

[72] A. V. Vlassov, S. Magdaleno, R. Setterquist, and R. Conrad, "Exosomes: current knowledge of their composition, biological 
functions, and diagnostic and therapeutic potentials," Biochimica et Biophysica Acta, vol. 1820, no. 7, pp. 940-948, 2012.

[73] D. Ben-Shushan, E. Markovsky, H. Gibori, G. Tiram, A. Scomparin, and R. Satchi-Fainaro, "Overcoming obstacles in microRNA delivery towards improved cancer therapy," Drug Delivery and Translational Research, vol. 4, no. 1, pp. 38-49, 2014.

[74] B. Peng, Y. Chen, and K. W. Leong, "MicroRNA delivery for regenerative medicine," Advanced Drug Delivery Reviews, vol. 88, pp. 108-122, 2015.

[75] G. Hu, K. M. Drescher, and X. M. Chen, "Exosomal miRNAs: biological properties and therapeutic potential," Frontiers in Genetics, vol. 3, p. 56, 2012.

[76] A. G. E. Ibrahim, K. Cheng, and E. Marbán, "Exosomes as critical agents of cardiac regeneration triggered by cell therapy," Stem Cell Reports, vol. 2, no. 5, pp. 606-619, 2014.

[77] H. Xin, Y. Li, B. Buller et al., "Exosome-mediated transfer of MiR-133b from multipotent mesenchymal stromal cells to neural cells contributes to neurite outgrowth," Stem Cells, vol. 30, no. 7, pp. 1556-1564, 2012.

[78] L. Poliseno, A. Tuccoli, L. Mariani et al., "MicroRNAs modulate the angiogenic properties of HUVECs," Blood, vol. 108, no. 9, pp. 3068-3071, 2006.

[79] D. Li, X. Li, A. Wang et al., "MicroRNA-31 promotes skin wound healing by enhancing keratinocyte proliferation and migration," The Journal of Investigative Dermatology, vol. 135, no. 6, pp. 1676-1685, 2015.

[80] S. Zhou, P. Zhang, P. Liang, and X. Huang, "The expression of $\mathrm{miR}-125 \mathrm{~b}$ regulates angiogenesis during the recovery of heatdenatured HUVECs," Burns, vol. 41, no. 4, pp. 803-811, 2015.

[81] X. Li, D. Li, J. D. Wikstrom et al., "MicroRNA-132 promotes fibroblast migration via regulating RAS P21 protein activator 1 in skin wound healing," Scientific Reports, vol. 7, no. 1, p. 7797, 2017.

[82] L. Fan, Q. Wu, X. Xing, Y. Wei, and Z. Shao, "MicroRNA-145 targets vascular endothelial growth factor and inhibits invasion and metastasis of osteosarcoma cells," Acta Biochimica et Biophysica Sinica, vol. 44, no. 5, pp. 407-414, 2012.

[83] J. Ahn, H. Lee, C. H. Jung, and T. Jeon, "MicroRNA-146b promotes adipogenesis by suppressing the SIRT1-FOXO1 cascade," EMBO Molecular Medicine, vol. 5, no. 10, pp. 1602-1612, 2013.

[84] H. Lang, F. Zhao, T. Zhang et al., "MicroRNA-149 contributes to scarless wound healing by attenuating inflammatory response," Molecular Medicine Reports, vol. 16, no. 2, pp. 2156-2162, 2017.

[85] S. C. Slater, E. Jover, A. Martello et al., "MicroRNA-532-5p regulates pericyte function by targeting the transcription regulator BACH1 and angiopoietin-1," Molecular Therapy, vol. 26, no. 12, pp. 2823-2837, 2018.

[86] P. Bao, A. Kodra, M. Tomic-Canic, M. S. Golinko, H. P. Ehrlich, and H. Brem, "The role of vascular endothelial growth factor in wound healing," Journal of Surgical Research, vol. 153, no. 2, pp. 347-358, 2009.

[87] J. F. Li, H. F. Duan, C. T. Wu et al., "HGF accelerates wound healing by promoting the dedifferentiation of epidermal cells through -integrin/ILK pathway," BioMed Research International, vol. 2013, Article ID 470418, 9 pages, 2013.

[88] R. Guo, L. Chai, L. Chen et al., "Stromal cell-derived factor 1 (SDF-1) accelerated skin wound healing by promoting the migration and proliferation of epidermal stem cells," In Vitro
Cellular \& Developmental Biology - Animal, vol. 51, no. 6, pp. 578-585, 2015.

[89] R. Salcedo, K. Wasserman, H. A. Young et al., "Vascular endothelial growth factor and basic fibroblast growth factor induce expression of CXCR4 on human endothelial cells," The American Journal of Pathology, vol. 154, no. 4, pp. 1125-1135, 1999.

[90] T. Yamamoto, B. Eckes, C. Mauch, K. Hartmann, and T. Krieg, "Monocyte chemoattractant protein-1 enhances gene expression and synthesis of matrix metalloproteinase-1 in human fibroblasts by an autocrine IL- $1 \alpha$ loop," Journal of Immunology, vol. 164, no. 12, pp. 6174-6179, 2000.

[91] E. Engelhardt, A. Toksoy, M. Goebeler, S. Debus, E. B. Bröcker, and R. Gillitzer, "Chemokines IL-8, GRO $\alpha$, MCP-1, IP-10, and Mig are sequentially and differentially expressed during phasespecific infiltration of leukocyte subsets in human wound healing," The American Journal of Pathology, vol. 153, no. 6, pp. 1849-1860, 1998. 